\title{
Synthesis and structure-activity relationships studies of brartemicin analogs as anti-invasive agents
}

\author{
Yong-Li Jiang ${ }^{1}$, Satoshi Miyanaga ${ }^{2}$, Xiu-Zhen Han $^{1}$, Long-Qiang Tang ${ }^{1}$, Yasuhiro Igarashi ${ }^{2}$, Ikuo Saiki ${ }^{3}$ \\ and Zhao-Peng Liu ${ }^{1}$
}

Brartemicin is a trehalose-based inhibitor of tumor cell invasion produced by the actinomycete of the genus Nonomuraea. In order to find more potent anti-invasive agents and study the structure-activity relationships, a series of 19 brartemicin analogs were prepared via two synthetic routes from $\alpha, \alpha$-D-trehalose and evaluated for their anti-invasive activities. Compound 4f, 6,6'-bis(2,3-dimethoxybenzoyl)- $\alpha, \alpha$-D-trehalose, was more potent than the natural brartemicin. It inhibited the invasion of murine colon 26-L5, colon carcinoma SW620, melanoma B16-BL6 and breast MDA-MB-231 cells with IC $_{50}$ values of 0.15 , $2.35,4.12$ and $2.61 \mu \mathrm{M}$, respectively. Analog $4 \mathrm{p}, 6,6^{\prime}$-bis(3,4-dimethoxycinnamoyl)- $\alpha, \alpha$-D-trehalose, was as potent as brartemicin against invasion of murine colon 26-L5 carcinoma cells in vitro. The structure-activity relationships of these novel trehalose-based compounds were summarized.

The Journal of Antibiotics (2013) 66, 531-537; doi:10.1038/ja.2013.37; published online 8 May 2013

Keywords: brartemicin; trehalose; anti-invasive; anti-metastatic; metastasis

\section{INTRODUCTION}

Metastasis, the spread of malignant cells from a primary tumor to distant sites, poses the biggest problem to cancer treatment and is responsible for $90 \%$ of cancer patient deaths. ${ }^{1}$ It occurs in a series of discrete steps, including the detachment of cancer cells from primary tumor, migration, adhesion and invasion of cancer cells into the blood or lymphatic vessels, extravasation out of the vessel, and finally, interactions with the target tissue and grows out to secondary tumors. ${ }^{2}$ Advances in the successful treatment of cancer by existing approaches, such as surgery and chemotherapy, remain limited by the presence of metastatic disease. As invasion is crucial at all the different steps of the metastasis process and closely related to the final outcome of cancer, the development of anti-invasive and anti-metastasis drugs by specifically inhibiting the invasive behavior of tumor cells is extremely attractive. ${ }^{3,4}$

In recent years, many natural products have been identified to have good activities against tumor invasion and metastasis. ${ }^{5,6} 6,6^{\prime}$-bis $(2,4-$ dihydroxy-6-methylbenzoyl)- $\alpha, \alpha$-D-trehalose (Brartemicin, 1) was recently isolated from the culture broth of the actinomycete of the genus Nonomuraea. It can inhibit the invasion of murine colon carcinoma 26-L5 cells with an $\mathrm{IC}_{50}$ value of $0.25 \mu \mathrm{g} \mathrm{ml}^{-1}$, and has no cytotoxicity against the same cell line even at the concentration of

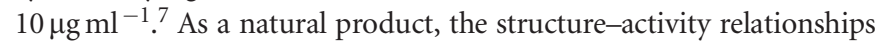

of brartemicin are not clear. In a previous communication, we reported the synthesis and evaluation of nine brartemicin analogs as anti-invasive agents. ${ }^{8}$ We extended this study and reported here the preparation of a total of 19 brartemicin derivatives having diverse substituents at the 6,6'-positions of $\alpha, \alpha$-D-trehalose, structure-activity relationship investigations and in vitro anti-invasive activities.

\section{RESULTS AND DISCUSSION}

Synthesis of brartemicin analogs

$6,6^{\prime}$-Di-O-acyl-chemical modification of trehalose is one of the most effective approaches for the understanding of the biological potential of these compounds. ${ }^{9,10}$ To find potent anti-invasive agents and investigate the structure-activity relationships, a diverse group of trehalose esters with aromatic, heterocyclic and aliphatic substituents at the $6,6^{\prime}$-positions of $\alpha, \alpha$-D-trehalose were designed. These brartemicin analogs were prepared via two synthetic routes (methods A and B). These synthesis plans relied either on a useful difference in reactivity between the primary and secondary hydroxyl groups of trehalose or on suitably blocked molecules.

As shown in Scheme 1, method A adopted benzyl as the secondary hydroxyl protective group. The benzyl-protected trehalose 2 was prepared by a slight modification of Gilbertson's procedures ${ }^{11}$ with an improved yield from 25 to $35 \%$ as described in the previous

\footnotetext{
${ }^{1}$ Department of Organic Chemistry, Key Laboratory of Chemical Biology (Ministry of Education), School of Pharmaceutical Sciences, Shandong University, Jinan, China; ${ }^{2}$ Biotechnology Research Center, Toyama Prefectural University, 5180 Kurokawa, Imizu, Toyama, Japan and ${ }^{3}$ Department of Bioscience, Institute of Natural Medicine, University of Toyama, Toyama, Japan

Correspondence: Professor Z-P Liu, Department of Organic Chemistry, Key Laboratory of Chemical Biology (Ministry of Education), School of Pharmaceutical Sciences, Shandong University, No. 44 Wenhua Xilu, Jinan 250012, Shandong Province, China.

E-mail: liuzhaop@sdu.edu.cn

Or Professor Y Igarashi, Biotechnology Research Center, Toyama Prefectural University, 5180 Kurokawa, Imizu, Toyama 939-0398, Japan.

E-mail: yas@pu-toyama.ac.jp
}

Received 10 October 2012; revised 23 March 2013; accepted 5 April 2013; published online 8 May 2013 

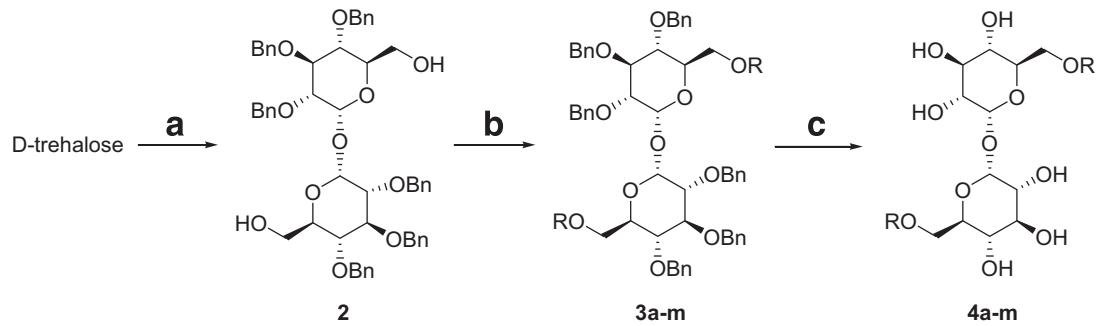

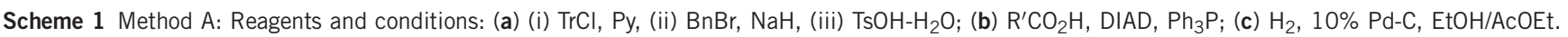

Table 1 Synthesis of brartemicin analogs and their anti-invasive activity in vitro

\begin{tabular}{|c|c|c|c|c|c|}
\hline \multirow[b]{2}{*}{ Entry } & \multirow[b]{2}{*}{$R$} & \multicolumn{2}{|c|}{ Yield \% } & \multicolumn{2}{|c|}{ Murine colon 26-L5 cells } \\
\hline & & $3 a-s$ & $4 a-s$ & Compounds & $1 C_{50}(\mu \mathrm{M})$ \\
\hline 1 & 2-MeO-benzoyl & $3 a, 83$ & $4 a, 70$ & $4 a$ & 1.64 \\
\hline 2 & 2-Me-benzoyl & $3 b, 88$ & $4 b, 63$ & $4 \mathrm{~b}$ & $N A^{a}$ \\
\hline 3 & 2-OH-benzoyl & $3 c, 68$ & $4 c, 65$ & $4 c$ & $>1.71^{\mathrm{b}}$ \\
\hline 4 & 4-MeO-benzoyl & $3 d, 82$ & $4 d, 70$ & $4 d$ & NA \\
\hline 5 & 4-BnO-(3e) or 4-OH-benzoyl (4e) & $3 e, 68$ & $4 e, 65$ & $4 e$ & 1.72 \\
\hline 6 & 2,3-(MeO) $)_{2}$-benzoyl & $3 f, 74$ & $4 f, 60$ & $4 f$ & 0.15 \\
\hline 7 & 2-BnO-3-MeO-(3g) or 2-OH-3-MeO-benzoyl (4g) & $3 g, 69$ & $4 g, 70$ & $4 \mathrm{~g}$ & NA \\
\hline 8 & 2,4-(MeO) $)_{2}$-benzoyl & 3h, 75 & $4 h, 62$ & $4 \mathrm{~h}$ & NA \\
\hline 9 & $2,4-(\mathrm{BnO})_{2}-(3 \mathbf{i})$ or 2,4-(OH) $)_{2}$-benzoyl $(4 \mathbf{i})$ & $3 i, 76$ & $4 \mathbf{i}, 71$ & $4 i$ & NA \\
\hline 10 & 2,6-F -benzoyl $^{2}$ & $3 \mathrm{j}, 83$ & $4 \mathrm{j}, 66$ & $4 j$ & 1.60 \\
\hline 11 & 2-Me-6-NO ${ }_{2}$-(3k) or 2-EtNH-6-Me-benzoyl (4k) & $3 k, 77$ & $4 k, 36$ & $4 k$ & 1.64 \\
\hline 12 & 4-F-3-MeO-benzoyl & 31,76 & $4 \mathrm{I}, 71$ & $4 !$ & NA \\
\hline 13 & 3,4,5-(MeO) $)_{3}$-benzoyl & $3 m, 69$ & $4 m, 59$ & $4 m$ & NA \\
\hline 14 & 2,6-Cl - -benzoyl & $3 n, 69$ & $4 n, 62$ & $4 n$ & $>1.45^{\mathrm{C}}$ \\
\hline 15 & Cinnamoyl & 3o, 84 & 40,86 & 40 & NA \\
\hline 16 & 3,4-(MeO) $)_{2}$-cinnamoyl & $3 p, 78$ & $4 p, 83$ & $4 p$ & 0.33 \\
\hline 17 & Isonicotinoyl & $3 q, 78$ & $4 q, 71$ & $4 q$ & NA \\
\hline 18 & Pyrazine-2-carbonyl & $3 r, 85$ & $4 r, 67$ & $4 r$ & NA \\
\hline 19 & n-hexanoyl & $3 s, 89$ & $4 s, 91$ & $4 \mathrm{~s}$ & NA \\
\hline 20 & 2,3-(OH) ${ }_{2}$-benzoyl & & & $4 \mathrm{t}^{\mathrm{d}}$ & $>1.63^{\mathrm{e}}$ \\
\hline 21 & 2,4-(OH) $2_{2}-6-$ Me-benzoyl & & & brartemicin (1) & 0.39 \\
\hline
\end{tabular}

${ }^{a}$ No activity.

b35\% inhibition at $1.71 \mu \mathrm{m}$.

${ }^{3} 30 \%$ inhibition at $1.45 \mu \mathrm{m}$.

${ }^{\mathrm{d}}$ ggarashi et al. ${ }^{ }$

$\mathrm{e}_{40 \%}$ inhibition at $1.63 \mu \mathrm{m}$

report. ${ }^{8}$ The esterification was best achieved via the Mitsunobu reaction $^{12,13}$ in anhydrous THF in the presence of triphenylphosphine and DIAD (diisopropyl azodicarboxylate) to give the intermediates $3 \mathrm{a}-\mathrm{m}$ in yields ranging from 64 to $88 \%$. Finally, removal of the benzyl protective groups and functionality alteration under hydrogenolysis conditions generated the brartemicin analogs $\mathbf{4 a}-\mathbf{m}$ in generally good yields. The results are summarized in Table 1.

For those compounds having the functional groups that could not tolerate the hydrogenolysis conditions or those that could be prepared only in poor yields by method A, we prepared them by method B as shown in Scheme 2.

The hexasilylated trehalose $\mathbf{5}$ was prepared following Gensler's procedures. ${ }^{14}$ Treatment trehalose with trimethylsilyl chloride in dry pyridine gave the octa(trimethylsilyl) trehalose, which could be selectively desilylated to hexasilylated trehalose $\mathbf{5}$ having both primary hydroxyl groups exposed. Coupling reaction of the alcohol with various acids in the presence of DCC and DMAP led to the protected esters $\mathbf{3 n}-\mathbf{s}$ in good yields (69-89\%). Finally, removal of TMS protective groups under catalytic acid conditions gave the brartemicin analogs $\mathbf{4 n}-\mathbf{s}$ in high yields (Table 1).

\section{Structure-activity relationships of brartemicin analogs}

The synthetic trehalose-based compounds were tested for in vitro inhibitory activity against invasion of murine colon 26-L5 cells using Transwell chamber with $8.0-\mu \mathrm{m}$-diameter polyvinylpyrrolidone-free carbonate filters coated with matrigel. ${ }^{15,16}$ Cytotoxicity was also examined in the same cell line. All compounds tested exhibited no cytotoxicity even at the concentration of $80 \mu \mathrm{m}$. The anti-invasion assay results are summarized in Table 1. Two compounds exhibited very strong anti-invasive activities. Analog $\mathbf{4 f}$ having 2,3-dimethoxybenzoyl moieties was the most potent with an $\mathrm{IC}_{50}$ of $0.15 \mu \mathrm{M}$, and 2.6 -fold more potent than brartemicin $(0.39 \mu \mathrm{M})$ against invasion of murine colon 26-L5 cells. It was also potent towards SW620 colon 


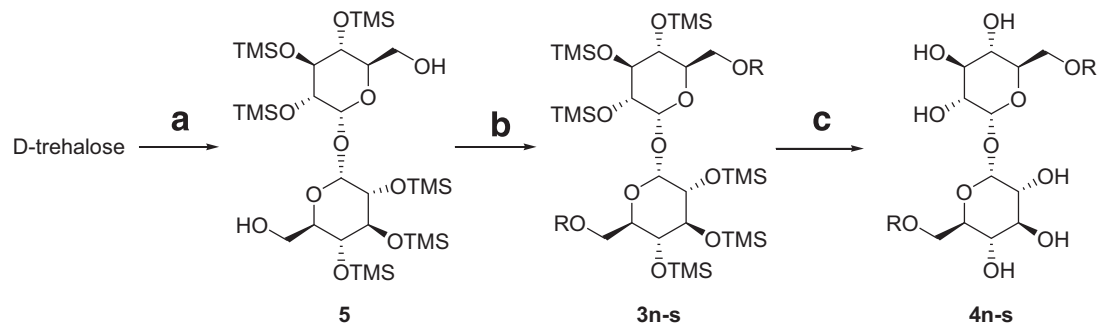

Scheme 2 Method B: Reagents and conditions: (a) (i) TMSCl, Py, (ii) $\mathrm{HOAc}, \mathrm{H}_{2} \mathrm{O}, \mathrm{Py}$; (b) $\mathrm{R}^{\prime} \mathrm{CO}_{2} \mathrm{H}$, DCC, DMAP, $\mathrm{CH}_{2} \mathrm{Cl}_{2}$; (c) $\mathrm{HOAc}^{(c a t .)}, \mathrm{MeOH}_{2} \mathrm{H}_{2} \mathrm{O}$, reflux.

carcinoma cells, B16-BL6 melanoma cells and MDA-MB-231 breast cancer cells, having $\mathrm{IC}_{50}$ values of $2.35,4.12$ and $2.61 \mu \mathrm{M}$, respectively. The 3,4-dimethoxycinnamic acid ester $4 \mathbf{p}$ has an $\mathrm{IC}_{50}$ of $0.33 \mu \mathrm{M}$, and is just as potent as natural brartemicin. Four compounds (4a, 4e, 4j and $4 \mathbf{k}$ ) were potent against invasion of murine colon 26-L5 cells; their $\mathrm{IC}_{50}$ values were at $1.0 \mu \mathrm{g} \mathrm{ml}^{-1}$ level. Analogs $4 \mathrm{c}$ and $4 \mathrm{n}$ were of moderate activity.

As brartemicin is a 6,6'-dibenzoyltrehalose, a variety of substituents on the phenyl ring were investigated for their effects on the antiinvasive activities. Among the mono-substituted compounds with different functionality at the 2-position of the benzoic acid ring, the 2-methyl substituted analog $\mathbf{4 b}$ was not active, while the 2-hydroxy and 2-methoxy substituted derivatives $4 \mathbf{c}$ and $4 \mathrm{a}$ maintained the antiinvasive activity (entries 3 and 1). This indicated that a hydrogen donor or acceptor group at the 2-position of the phenyl ring might be important for the activity. On the other hand, the 4-hydroxybenzoic acid derivative $4 \mathrm{e}$ (entry 5) was potent and had an $\mathrm{IC}_{50}$ of $1.72 \mu \mathrm{M}$, while its methylated analog $\mathbf{4 d}$ (entry 4 ) completely lost anti-invasive activity. This stressed the subtle bulkiness or polarity requirements at the 4-position of the phenyl ring.

Among the disubstituted benzoic acid ester series, the 2,3dimethoxy-substituted analog $4 \mathrm{f}$ was not only much more potent than its 2,3-dihydroxy counterpart $\mathbf{4 t}$ (entry 20), but also superior to the natural brartemicin. However, the 2-hydroxy-3-methoxy-benzoate $\mathbf{4 g}$ (entry 7) was not active. It seemed that the methoxy group at the 2-position of 2,3-disubstituted analogs might be crucial for their antiinvasive activity. In comparison with the active 2-methoxy- and 4-hydroxy-substituted analogs $\mathbf{4 a}$ and $\mathbf{4 e}$, the 2,4-dimethoxybenzoate 4h and 2,4-dihydroxybenzoate $\mathbf{4 i}$ were not active. Therefore, the disubstitution at the 2,4-positions was not favored for the antiinvasive activity. In general, the disubstitution at the 2,6-positions was well tolerated; both the 2,6-difluoro- and 2-ethylamino-6-methylbenzoic acid esters $4 \mathbf{j}$ and $\mathbf{4 k}$ (entries 10 and 11 ) were potent, while the 2,6-dichloro-substituted analog $\mathbf{4 n}$ (entry 14) had a decreased activity. Moreover, the 4-fluoro-3-methoxy-substituted and 3,4,5-trimethoxybenzoic esters $4 \mathbf{l}$ and $\mathbf{4 m}$ (entries 12 and 13) exhibited no anti-invasive abilities.

The replacements of the benzoyl moiety in brartemicin with heterocyclic or aliphatic acyl groups led to the loss of activities (analogs 3q-s, entries 17-19). This stressed the importance of the benzoyl moiety for the anti-invasive activity. Further investigation was made by placing an ethylene spacer between the phenyl and the carbonyl group. Though the cinnamate 4o was not active, the 3,4-dimethoxy-cinnamate $4 \mathbf{p}$ was just as potent as the natural brartemicin. This again emphasized the importance of the substituents on the phenyl ring. Moreover, as the 4-methoxy-substituted benzoate analogs were in general not active, the cinnamate counterparts may have different substituent requirements for the anti-invasive activity. This provided a structural basis for further modifications.

\section{CONCLUSION}

In summary, a series of 19 novel trehalose-based brartemicin analogs were synthesized and evaluated for their anti-invasive activity. Compound $4 \mathrm{f}$ was more potent than the natural brartemicin. It inhibited the invasion of murine colon 26-L5, colon carcinoma SW620, melanoma B16-BL6 and breast MDA-MB-231 cells with $\mathrm{IC}_{50}$ values of $0.15,2.35,4.12$ and $2.61 \mu \mathrm{M}$, respectively. The 3,4-dimethoxy-cinnamate $\mathbf{4 p}$ was also as potent as brartemicin. For the mono-substituted benzoates, substitution with a methoxy group at the 2-position was preferred, while substitution with a hydroxyl group at either 2- or 4-position maintained the potency. For the disubstituted benzoates, the substitution with methoxy group at the 2,3-positions gave the best results, and the 2-methoxy group was crucial for the activity, while for the 2,6-disubstituted benzoates, the substitution with a methoxy-, ethylamino-, fluoro- or chloro- group at the 2-position was well tolerated. In addition, introducing an ethylene spacer between the phenyl ring and the carbonyl group could also lead to potent analogs. These findings demonstrated that the trehalose-based compound was a new and interesting scaffold for the development of anti-invasive and anti-metastatic agents.

\section{EXPERIMENTAL PROCEDURE}

\section{Chemistry}

Melting points were determined on an X-6 micro-melting point apparatus (Beijing Tech. Co Ltd, Beijing, China) and are uncorrected. ${ }^{1} \mathrm{H}$ and ${ }^{13} \mathrm{C}-\mathrm{NMR}$ $(600 \mathrm{MHz})$ spectra were recorded at room temperature on a Bruker-500 NMR spectrometer, and all chemical shifts were reported as $\delta$ values (p.p.m.) relative to $\mathrm{Me}_{4} \mathrm{Si}(0.00$ p.p.m.) as internal standards. Electrospray-ionization MS (ESIMS) was performed on an API 4000 instrument. Column chromatography was performed on silica gel (200-300 mesh). Independent analysis of purity for synthetic products was achieved using analytical HPLC system (column, YMCPack SL12S05-2546JT A-003; flow rate, $1.0 \mathrm{ml} \mathrm{min}^{-1}$; gradient, $10-90 \%$ acetonitrile, $90-10 \%$ water $(0.1 \%$ TFA $)$ over $40 \mathrm{~min}$. All the compounds are of high purities $(>98.5 \%)$. All reactions involving oxygen- or moisturesensitive compounds were carried out under a dry $\mathrm{N}_{2}$ atmosphere. Unless otherwise noted, reagents were added by syringe. THF was distilled from sodium/benzophenone immediately before use.

$2,2^{\prime}, 3,3^{\prime}, 4,4^{\prime}$-Hexabenzyl- $\alpha, \alpha$-D-trehalose (2). This compound was prepared by a slight modification of Gilbertson's procedures. ${ }^{11}$ To a clear solution of trehalose dihydrate $(10.0 \mathrm{~g}, 26.43 \mathrm{mmol})$ in dried pyridine $(120 \mathrm{ml})$ was added triphenylmethyl chloride $(36.84 \mathrm{~g}, 132.16 \mathrm{mmol})$. The mixture was stirred under $\mathrm{N}_{2}$ at $40^{\circ} \mathrm{C}$ for $16 \mathrm{~h}$. Dry $\mathrm{MeOH}(80 \mathrm{ml})$ was added and the reaction mixture was stirred for another $30 \mathrm{~min}$. Evaporation of solvent afforded yellowish solid, which was mixed with $\mathrm{Et}_{2} \mathrm{O}(200 \mathrm{ml})$. Filtration and washing 
the solid with $\mathrm{Et}_{2} \mathrm{O}$ for several times until the disappearance of the trityl residue checked by TLC followed by washing with $3 \% \mathrm{NaHCO}_{3}$ solution and drying in vacuum gave a white solid $(25 \mathrm{~g})$.

The crude bistritylated trehalose was dissolved in DMF $(200 \mathrm{ml})$ and added $80 \% \mathrm{NaH}(15.86 \mathrm{~g}, 528.60 \mathrm{mmol})$. After stirring under nitrogen at room temperature for $1 \mathrm{~h}$, benzyl bromide $(37.7 \mathrm{ml}, 317.2 \mathrm{mmol})$ was added and the reaction mixture was stirred for $48 \mathrm{~h}$. Distillation under vacuum removed most of the solvent and the residue was diluted with EtOAc. Ice water was then added. The aqueous layer was extracted with EtOAc, and the combined organic layers were washed with brine and dried over $\mathrm{Na}_{2} \mathrm{SO}_{4}$. After evaporation of solvent, the yellowish oil was dissolved in $\mathrm{CH}_{2} \mathrm{Cl}_{2}(100 \mathrm{ml})$ and $\mathrm{MeOH}$ $(100 \mathrm{ml})$ and $\mathrm{TsOH}-\mathrm{H}_{2} \mathrm{O}(15.1 \mathrm{~g}, 79.3 \mathrm{mmol})$ was added. After stirring for $12 \mathrm{~h}$, the reaction was quenched with $5 \mathrm{ml}$ of $\mathrm{Et}_{3} \mathrm{~N}$. Evaporation of solvent and purification of the crude product by gradient flash silica gel chromatography (hexane/ethyl acetate: $4 \sim 1 / 1$ ) afforded 2 as a viscous oil ( $8.20 \mathrm{~g}, 35 \%$ ).

\section{Preparation of intermediates $3 \mathbf{a}-\mathbf{m}$}

$2,2^{\prime}, 3,3^{\prime}, 4,4^{\prime}$-Hexabenzyl-6,6'-bis(2-methoxybenzoyl)- $\alpha, \alpha$-D-trehalose (3a). Triphenylphosphine $(300 \mathrm{mg}, 1.14 \mathrm{mmol})$, 2-methoxybenzoic acid $(155 \mathrm{mg}$, $1.02 \mathrm{mmol})$ and di-isopropyl azodicarboxylate $(226 \mu \mathrm{l}, 1.14 \mathrm{mmol})$ were added to a stirred solution of $2(300 \mathrm{mg}, 0.34 \mathrm{mmol})$ in dry THF $(10 \mathrm{ml})$ at $0{ }^{\circ} \mathrm{C}$. After stirring for $2 \mathrm{~h}$ at the same temperature, the reaction mixture was diluted with ice water and extracted with EtOAc. The organic layer was dried over anhydrous $\mathrm{Na}_{2} \mathrm{SO}_{4}$, filtered and concentrated. The residue was purified by silica gel column chromatography (hexane/EtOAc, 15 3:1) to give 3a $(324.9 \mathrm{mg}, 83 \%)$ as a colorless oil. ${ }^{1} \mathrm{H}$ NMR $\left(600 \mathrm{MHz}, \mathrm{CDCl}_{3}\right) \delta 7.74(\mathrm{dd}$, $J=1.8,7.2 \mathrm{~Hz}, 1 \mathrm{H}), 7.45(\mathrm{td}, J=9.0,1.8 \mathrm{~Hz}, 1 \mathrm{H}), 7.24-7.38(\mathrm{~m}, 15 \mathrm{H}), 6.92-$ $6.95(\mathrm{~m}, 2 \mathrm{H}), 5.22(\mathrm{~d}, J=3.6 \mathrm{~Hz}, 1 \mathrm{H}), 5.04(\mathrm{~d}, J=10.8 \mathrm{~Hz}, 1 \mathrm{H}), 4.90$ (d, $J=10.8 \mathrm{~Hz}, 1 \mathrm{H}), 4.87(\mathrm{~d}, J=10.8 \mathrm{~Hz}, 1 \mathrm{H}), 4.70(\mathrm{~s}, 2 \mathrm{H}), 4.60(\mathrm{~d}, J=10.8$ $\mathrm{Hz}, 1 \mathrm{H}), 4.31-4.37(\mathrm{~m}, 3 \mathrm{H}), 4.09(\mathrm{t}, J=9.6 \mathrm{~Hz}, 1 \mathrm{H}), 3.82(\mathrm{~s}, 3 \mathrm{H}), 3.73$ (t, $J=9.6 \mathrm{~Hz}, 1 \mathrm{H}), 3.58(\mathrm{dd}, J=3.6,9.6 \mathrm{~Hz}, 1 \mathrm{H})$; MS (ESI) $m / z 1151.5[\mathrm{MH}]^{+}$.

Following the same procedures described for $\mathbf{3 a}$, intermediates $\mathbf{3 b}-\mathbf{m}$ were prepared.

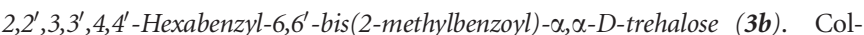
orless oil; $88 \%$. ${ }^{1} \mathrm{H}$ NMR $\left(600 \mathrm{MHz}, \mathrm{CDCl}_{3}\right) \delta 7.82(\mathrm{~d}, J=7.2 \mathrm{~Hz}, 1 \mathrm{H}), 7.18$ $7.39(\mathrm{~m}, 18 \mathrm{H}), 5.22(\mathrm{~d}, J=3.6 \mathrm{~Hz}, 1 \mathrm{H}), 5.01(\mathrm{~d}, J=10.8 \mathrm{~Hz}, 1 \mathrm{H}), 4.89$ $(\mathrm{d}, J=10.8 \mathrm{~Hz}, 2 \mathrm{H}), 4.70(\mathrm{q}, J=11.4 \mathrm{~Hz}, 2 \mathrm{H}), 4.58(\mathrm{~d}, J=10.8 \mathrm{~Hz}, 1 \mathrm{H})$, $4.27-4.36(\mathrm{~m}, 3 \mathrm{H}), 4.11(\mathrm{t}, J=9.6 \mathrm{~Hz}, 1 \mathrm{H}), 3.65(\mathrm{t}, J=9.6 \mathrm{~Hz}, 1 \mathrm{H}), 3.60$ (dd, $J=3.0,9.6 \mathrm{~Hz}, 1 \mathrm{H}), 2.60(\mathrm{~s}, 3 \mathrm{H})$; MS (ESI) $\mathrm{m} / z 1119.5[\mathrm{MH}]^{+}$.

2,2',3,3',4,4'-Hexabenzyl-6,6'-bis(2-hydroxybenzoyl)- $\alpha, \alpha$-D-trehalose (3c). Colorless oil; $68 \%$. ${ }^{1} \mathrm{H}$ NMR $\left(600 \mathrm{MHz}, \mathrm{CDCl}_{3}\right) \delta 10.60(\mathrm{~s}, 1 \mathrm{H}), 7.68(\mathrm{dd}, J=7.8$ $1.8 \mathrm{~Hz}, 1 \mathrm{H}), 7.42(\mathrm{t}, J=6.6 \mathrm{~Hz}, 1 \mathrm{H}), 7.23-7.39(\mathrm{~m}, 15 \mathrm{H}), 6.95(\mathrm{~d}, J=8.4 \mathrm{~Hz}$, $1 \mathrm{H}), 6.83(\mathrm{t}, J=7.8,7.2 \mathrm{~Hz}, 1 \mathrm{H}), 5.20(\mathrm{~d}, J=3.5 \mathrm{~Hz}, 1 \mathrm{H}), 5.05(\mathrm{~d}, J=10.8 \mathrm{~Hz}$, $2 \mathrm{H}), 4.92(\mathrm{dd}, J=8.4 \mathrm{~Hz}, 2 \mathrm{H}), 4.60(\mathrm{~d}, J=11.4 \mathrm{~Hz}, 2 \mathrm{H}), 4.27-4.32(\mathrm{~m}, 2 \mathrm{H})$, $4.19(\mathrm{dd}, J=3.0,9.0 \mathrm{~Hz}, 1 \mathrm{H}), 4.12(\mathrm{t}, J=9.0,9.6 \mathrm{~Hz}, 1 \mathrm{H}), 3.61-3.66(\mathrm{~m}, 2 \mathrm{H})$; MS (ESI) $m / z 1123.5[\mathrm{MH}]^{+}$.

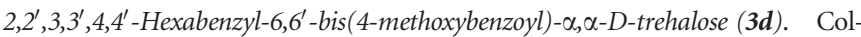
orless oil; $82 \% .{ }^{1} \mathrm{H}$ NMR $\left(600 \mathrm{MHz}, \mathrm{CDCl}_{3}\right) \delta 7.92(\mathrm{~d}, J=8.4 \mathrm{~Hz}, 2 \mathrm{H})$, 7.23-7.38 (m, 15H), $6.88(\mathrm{~d}, J=8.4 \mathrm{~Hz}, 2 \mathrm{H}), 5.23(\mathrm{~d}, J=3.6 \mathrm{~Hz}, 1 \mathrm{H}), 5.03$ (d, $J=10.8 \mathrm{~Hz}, 1 \mathrm{H}), 4.89(\mathrm{t}, J=9.6 \mathrm{~Hz}, 2 \mathrm{H}), 4.72(\mathrm{q}, J=12.0 \mathrm{~Hz}, 2 \mathrm{H}), 4.58$ $(\mathrm{d}, J=10.8 \mathrm{~Hz}, 1 \mathrm{H}), 4.31-4.33(\mathrm{~m}, 2 \mathrm{H}), 4.26(\mathrm{dd}, J=3.6,12.6 \mathrm{~Hz}, 1 \mathrm{H}), 4.11$ $(\mathrm{t}, J=3.6 \mathrm{~Hz}, 1 \mathrm{H}), 3.83(\mathrm{~s}, 3 \mathrm{H}), 3.67(\mathrm{t}, J=9.6 \mathrm{~Hz}, 1 \mathrm{H}), 3.62(\mathrm{dd}, J=3.6$, $9.6 \mathrm{~Hz}, 1 \mathrm{H})$; MS (ESI) $\mathrm{m} / z$ 1151.5 $[\mathrm{MH}]^{+}$.

2,2',3,3',4,4'-Hexabenzyl-6,6'-bis(4-benzyloxybenzoyl)- $\alpha, \alpha$-D-trehalose (3e). Colorless oil; $68 \% .{ }^{1} \mathrm{H}$ NMR $\left(600 \mathrm{MHz}, \mathrm{CDCl}_{3}\right) \delta 7.92(\mathrm{~d}, J=9.0 \mathrm{~Hz}, 2 \mathrm{H})$, 7.22-7.43 (m, 20H), $6.94(\mathrm{~d}, J=9.0 \mathrm{~Hz}, 2 \mathrm{H}), 5.22(\mathrm{~d}, J=3.0 \mathrm{~Hz}, 1 \mathrm{H}), 5.10$ $(\mathrm{s}, 2 \mathrm{H}), 5.03(\mathrm{~d}, J=10.8 \mathrm{~Hz}, 1 \mathrm{H}), 4.90(\mathrm{t}, J=10.8 \mathrm{~Hz}, 2 \mathrm{H}), 4.72(\mathrm{q}, J=12.0 \mathrm{~Hz}$, $2 \mathrm{H}), 4.57(\mathrm{~d}, J=10.8 \mathrm{~Hz}, 1 \mathrm{H}), 4.30-4.33(\mathrm{~m}, 2 \mathrm{H}), 4.26(\mathrm{dd}, J=3.6,9.6 \mathrm{~Hz}, 1 \mathrm{H})$, $4.10(\mathrm{t}, J=9.6 \mathrm{~Hz}, 1 \mathrm{H}), 3.67(\mathrm{t}, J=9.6 \mathrm{~Hz}, 1 \mathrm{H}), 3.62(\mathrm{dd}, J=3.6,9.6 \mathrm{~Hz}, 1 \mathrm{H})$; MS (ESI) $m / z$ 1303.4 $[\mathrm{MH}]^{+}$.

2,2',3,3',4,4'-Hexabenzyl-6,6 -bis(2,3-dimethoxybenzoyl)- $\alpha, \alpha$-D-trehalose (3f). Colorless oil; $74 \%$. ${ }^{1} \mathrm{H}$ NMR $\left(600 \mathrm{MHz}, \mathrm{CDCl}_{3}\right) \delta 7.24-7.37$ (m, 16H), 7.02-7.05 (m, $2 \mathrm{H}), 5.20(\mathrm{~d}, J=3.6 \mathrm{~Hz}, 1 \mathrm{H}), 5.01(\mathrm{~d}, J=10.2 \mathrm{~Hz}, 1 \mathrm{H}), 4.88(\mathrm{dd}, J=7.8$, $10.8 \mathrm{~Hz}, 2 \mathrm{H}), 4.68(\mathrm{q}, J=12.0 \mathrm{~Hz}, 2 \mathrm{H}), 4.58(\mathrm{~d}, J=10.2 \mathrm{~Hz}, 1 \mathrm{H}), 4.38(\mathrm{dd}, J=3.6$, $12.0 \mathrm{~Hz}, \quad 1 \mathrm{H}), \quad 4.28-4.32 \quad(\mathrm{~m}, \quad 2 \mathrm{H}), \quad 4.08 \quad(\mathrm{t}, \quad J=9.6 \mathrm{~Hz}, \quad 1 \mathrm{H}), \quad 3.86$ (s, 3H), $3.84(\mathrm{~s}, 3 \mathrm{H}), 3.68$ (t, $J=9.6 \mathrm{~Hz}, 1 \mathrm{H}), 3.57$ (dd, $J=3.6,9.6 \mathrm{~Hz}, 1 \mathrm{H}) ; \mathrm{MS}$ (ESI) $\mathrm{m} / z 1211.5[\mathrm{MH}]^{+}$.

$2,2^{\prime}, 3,3^{\prime}, 4,4^{\prime}$-Hexabenzyl-6,6'-bis(2-benzyloxy-3-methoxybenzoyl)- $\alpha, \alpha$-D-trehalose (3g). Colorless oil; 69\%. ${ }^{1} \mathrm{H}$ NMR $\left(600 \mathrm{MHz}, \mathrm{CDCl}_{3}\right) \delta 7.50$ (d, $J=7.2$ $\mathrm{Hz}, 1 \mathrm{H}), 7.22-7.35(\mathrm{~m}, 20 \mathrm{H}), 7.05(\mathrm{dd}, J=3.6,4.8 \mathrm{~Hz}, 2 \mathrm{H}), 4.97-5.11(\mathrm{~m}$, $3 \mathrm{H}), 4.84(\mathrm{dd}, J=9.6,2.4 \mathrm{~Hz}, 2 \mathrm{H}), 4.60(\mathrm{~d}, J=2.4 \mathrm{~Hz}, 2 \mathrm{H}), 4.53(\mathrm{~d}, J=10.8$ $\mathrm{Hz}, 1 \mathrm{H}), 4.36(\mathrm{dd}, J=3.0,9.0 \mathrm{~Hz}, 1 \mathrm{H}), 4.24-4.29(\mathrm{~m}, 2 \mathrm{H}), 4.03(\mathrm{t}, J=9.6 \mathrm{~Hz}$, $1 \mathrm{H}), 3.85(\mathrm{~s}, 3 \mathrm{H}), 3.61(\mathrm{t}, J=9.6 \mathrm{~Hz}, 1 \mathrm{H}), 3.45(\mathrm{dd}, J=3.6,6.0 \mathrm{~Hz}, 1 \mathrm{H}) ; \mathrm{MS}$ (ESI) $\mathrm{m} / z 1363.6[\mathrm{MH}]^{+}$.

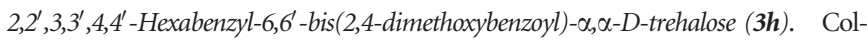
orless oil; $75 \%$. ${ }^{1} \mathrm{H}$ NMR $\left(600 \mathrm{MHz}, \mathrm{CDCl}_{3}\right) \delta 7.80(\mathrm{~d}, J=8.4 \mathrm{~Hz}, 1 \mathrm{H}), 7.22-7.39$ $(\mathrm{m}, \quad 15 \mathrm{H}), \quad 6.42-6.46 \quad(\mathrm{~m}, \quad 2 \mathrm{H}), \quad 5.22 \quad(\mathrm{~d}, \quad J=3.6 \mathrm{~Hz}, \quad 1 \mathrm{H}), \quad 5.03$ $(\mathrm{d}, J=10.8 \mathrm{~Hz}, 1 \mathrm{H}), 4.90(\mathrm{~d}, J=10.8 \mathrm{~Hz}, 1 \mathrm{H}), 4.85(\mathrm{~d}, J=10.8 \mathrm{~Hz}, 1 \mathrm{H}), 4.69$ (s, $2 \mathrm{H}), 4.58(\mathrm{~d}, J=10.8 \mathrm{~Hz}, 1 \mathrm{H}), 4.28-4.33(\mathrm{~m}, 3 \mathrm{H}), 4.08(\mathrm{t}, J=9.6 \mathrm{~Hz}, 1 \mathrm{H}), 3.82$ (s, 3H), 3.80 (s, 3H), $3.74(\mathrm{t}, J=9.6 \mathrm{~Hz}, 1 \mathrm{H}), 3.58$ (dd, $J=3.6,6.0 \mathrm{~Hz}, 1 \mathrm{H})$; MS (ESI) $\mathrm{m} / z 1211.5[\mathrm{MH}]^{+}$

2,2',3,3',4,4'-Hexabenzyl-6,6-bis(2,4-dibenzyloxybenzoyl)- $\alpha, \alpha$-D-trehalose (3i). Colorless oil; $76 \% .{ }^{1} \mathrm{H}$ NMR $\left(600 \mathrm{MHz}, \mathrm{CDCl}_{3}\right) \delta 7.78(\mathrm{~d}, J=7.2 \mathrm{~Hz}, 1 \mathrm{H})$, $7.23-7.44(\mathrm{~m}, 25 \mathrm{H}), 6.51(\mathrm{dd}, J=2.4,9.6 \mathrm{~Hz}, 2 \mathrm{H}), 5.18(\mathrm{~d}, J=3.6 \mathrm{~Hz}, 1 \mathrm{H})$, $5.12(\mathrm{~s}, 2 \mathrm{H}), 5.02(\mathrm{~d}, J=10.8 \mathrm{~Hz}, 1 \mathrm{H}), 5.00(\mathrm{dd}, J=8.4,10.2 \mathrm{~Hz}, 2 \mathrm{H}), 4.84$ $(\mathrm{dd}, J=7.8,9.0 \mathrm{~Hz}, 2 \mathrm{H}), 4.62(\mathrm{~d}, J=1.2 \mathrm{~Hz}, 2 \mathrm{H}), 4.57(\mathrm{~d}, J=7.8 \mathrm{~Hz}, 1 \mathrm{H}), 4.38$ (dd, $J=3.6,9.0 \mathrm{~Hz}, 1 \mathrm{H}), 4.29-4.33(\mathrm{~m}, 2 \mathrm{H}), 4.06(\mathrm{dd}, J=3.6,5.4 \mathrm{~Hz}, 1 \mathrm{H})$, $3.69(\mathrm{t}, J=9.6 \mathrm{~Hz}, 1 \mathrm{H}), 3.50(\mathrm{dd}, J=3.6,6.0 \mathrm{~Hz}, 1 \mathrm{H})$; MS (ESI) $\mathrm{m} / \mathrm{z} 1515.7$ $[\mathrm{MH}]^{+}$.

2,2',3,3',4,4'-Hexabenzyl-6,6'-bis(2,6-difluorobenzoyl)- $\alpha, \alpha$-D-trehalose (3j). Colorless oil; 83\%. ${ }^{1} \mathrm{H}$ NMR $\left(600 \mathrm{MHz}, \mathrm{CDCl}_{3}\right) \delta 7.25-7.41(\mathrm{~m}, 16 \mathrm{H}), 6.92$ $(\mathrm{t}, J=8.4 \mathrm{~Hz}, 2 \mathrm{H}), 5.20(\mathrm{~d}, J=3.6 \mathrm{~Hz}, 1 \mathrm{H}), 5.01(\mathrm{~d}, J=10.8 \mathrm{~Hz}, 1 \mathrm{H}), 4.89$ $(\mathrm{dd}, J=6.0,10.8 \mathrm{~Hz}, 2 \mathrm{H}), 4.68(\mathrm{q}, J=12.0 \mathrm{~Hz}, 2 \mathrm{H}), 4.59(\mathrm{~d}, J=10.2 \mathrm{~Hz}, 1 \mathrm{H})$, $4.35(\mathrm{dd}, J=3.6,12.6 \mathrm{~Hz}, 1 \mathrm{H}), 4.29(\mathrm{~d}, J=12.6 \mathrm{~Hz}, 2 \mathrm{H}), 4.06(\mathrm{t}, J=9.6 \mathrm{~Hz}$, $1 \mathrm{H}), 3.65(\mathrm{t}, J=9.6 \mathrm{~Hz}, 1 \mathrm{H}), 3.58(\mathrm{dd}, J=3.6,9.6 \mathrm{~Hz}, 1 \mathrm{H}) ; \mathrm{MS}(\mathrm{ESI}) \mathrm{m} / \mathrm{z}$ $1163.6[\mathrm{MH}]^{+}$.

2,2' $, 3,3^{\prime}, 4,4^{\prime}$-Hexabenzyl-6,6-bis(2-methyl-6-nitrobenzoyl)- $\alpha, \alpha$-D-trehalose (3k) Colorless oil; $77 \% .{ }^{1} \mathrm{H}$ NMR $\left(600 \mathrm{MHz}, \mathrm{CDCl}_{3}\right) \delta 7.94(\mathrm{~d}, J=7.8 \mathrm{~Hz}, 1 \mathrm{H})$, $7.49(\mathrm{~d}, J=7.8 \mathrm{~Hz}, 1 \mathrm{H}), 7.43(\mathrm{t}, J=7.8 \mathrm{~Hz}, 1 \mathrm{H}), 7.18-7.36(\mathrm{~m}, 15 \mathrm{H}), 5.17$ $(\mathrm{d}, J=3.6 \mathrm{~Hz}, 1 \mathrm{H}), 4.98(\mathrm{~d}, J=10.8 \mathrm{~Hz}, 1 \mathrm{H}), 4.85(\mathrm{dd}, J=6.0,10.8 \mathrm{~Hz}, 2 \mathrm{H})$, $4.57-4.62(\mathrm{~m}, 3 \mathrm{H}), 4.40(\mathrm{~s}, 2 \mathrm{H}), 4.29(\mathrm{~d}, J=10.2 \mathrm{~Hz}, 1 \mathrm{H}), 4.05(\mathrm{t}, J=9.6 \mathrm{~Hz}$, $1 \mathrm{H}), 3.48-3.52(\mathrm{~m}, 2 \mathrm{H}), 2.32(\mathrm{~s}, 3 \mathrm{H})$; MS (ESI) $\mathrm{m} / \mathrm{z} 1209.5[\mathrm{MH}]^{+}$.

2,2',3,3',4,4'-Hexabenzyl-6,6-bis(4-fluoro-3-methoxybenzoyl)- $\alpha, \alpha$-D-trehalose (3l). Colorless oil; $64 \% .{ }^{1} \mathrm{H}$ NMR $\left(600 \mathrm{MHz}, \mathrm{CDCl}_{3}\right) \delta 7.58(\mathrm{dd}, J=1.8,10.8 \mathrm{~Hz}$, $1 \mathrm{H}), 7.51(\mathrm{ddd}, J=1.8,4.2,6.6 \mathrm{~Hz}, 1 \mathrm{H}), 7.23-7.38(\mathrm{~m}, 15 \mathrm{H}), 7.06(\mathrm{dd}, J=8.4$, $10.8 \mathrm{~Hz}, 1 \mathrm{H}), 5.21(\mathrm{~d}, J=3.6 \mathrm{~Hz}, 1 \mathrm{H}), 5.03(\mathrm{~d}, J=10.2 \mathrm{~Hz}, 1 \mathrm{H}), 4.90(\mathrm{~d}$, $J=12.0 \mathrm{~Hz}, 2 \mathrm{H}), 4.71(\mathrm{q}, J=12.0 \mathrm{~Hz}, 2 \mathrm{H}), 4.58(\mathrm{~d}, J=10.8 \mathrm{~Hz}, 1 \mathrm{H}), 4.32(\mathrm{~d}$, $J=10.2 \mathrm{~Hz}, 2 \mathrm{H}), 4.26(\mathrm{dd}, J=4.2,12.0 \mathrm{~Hz}, 1 \mathrm{H}), 4.10(\mathrm{t}, J=9.6 \mathrm{~Hz}, 1 \mathrm{H}), 3.87$ (s, $3 \mathrm{H}), 3.63$ (d, $J=9.6 \mathrm{~Hz}, 1 \mathrm{H}), 3.59$ (dd, $J=3.6,9.6 \mathrm{~Hz}, 1 \mathrm{H})$; MS (ESI) $m / z$ $1187.5[\mathrm{MH}]^{+}$.

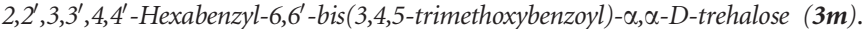
Colorless oil; 69\%. ${ }^{1} \mathrm{H}$ NMR (600 MHz, $\left.\mathrm{CDCl}_{3}\right) \delta 7.25-7.37$ (m, 15H), $7.22(\mathrm{~s}$, $2 \mathrm{H}), 5.22(\mathrm{~d}, J=3.6 \mathrm{~Hz}, 1 \mathrm{H}), 5.02(\mathrm{~d}, J=10.8 \mathrm{~Hz}, 1 \mathrm{H}), 4.90(\mathrm{dd}, J=3.0$, $10.8 \mathrm{~Hz}, 2 \mathrm{H}), 4.69(\mathrm{~s}, 2 \mathrm{H}), 4.60(\mathrm{~d}, J=10.8 \mathrm{~Hz}, 1 \mathrm{H}), 4.37(\mathrm{~d}, J=10.8 \mathrm{~Hz}, 1 \mathrm{H})$ $4.28-4.34(\mathrm{~m}, 2 \mathrm{H}), 4.10(\mathrm{t}, J=9.6 \mathrm{~Hz}, 1 \mathrm{H}), 3.88(\mathrm{~s}, 3 \mathrm{H}), 3.82(\mathrm{~s}, 6 \mathrm{H}), 3.59$ $(\mathrm{d}, J=9.6 \mathrm{~Hz}, 1 \mathrm{H}), 3.56(\mathrm{dd}, J=3.6,9.6 \mathrm{~Hz}, 1 \mathrm{H}) ; \mathrm{MS}(\mathrm{ESI}) \mathrm{m} / z 1271.6$ $[\mathrm{MH}]^{+}$.

Preparation of $2,2^{\prime}, 3,3^{\prime}, 4,4^{\prime}$-hexa(trimethylsilyl)- $\alpha, \alpha$-D-trehalose (5) Compound $\mathbf{5}$ was prepared following Gensler's procedures. ${ }^{14}$ To a solution of trehalose dihydrate $(10.0 \mathrm{~g}, 26.43 \mathrm{mmol})$ in dry pyridine $(100 \mathrm{ml})$ was added trimethylsilyl chloride $(50 \mathrm{ml}, 396 \mathrm{mmol})$ at room temperature dropwise. After stirring at room temperature for 1 day, the mixture was refluxed for $2 \mathrm{~h}$. 
Solvent was removed by distillation at reduced pressures. The residue, treated with $200 \mathrm{ml}$ of dry petroleum ether, was filtered. The crude persilylated trehalose was dissolved in dry pyridine $(100 \mathrm{ml})$. Water $(10 \mathrm{ml})$ and glacial acetic acid $(3.3 \mathrm{ml})$ was then added at $8{ }^{\circ} \mathrm{C}$. The cold solution was stirred under $\mathrm{N}_{2}$ for $14 \mathrm{~h}$. The reaction mixture was poured over crushed ice and water $(200 \mathrm{ml})$, and the two-phase system was extracted with several portions of petroleum ether. After the combined extract was washed several times with cold water, the organic layer was dried and concentrated. Purification of the crude product by gradient flash silica gel chromatography (hexane/ethyl acetate: $20 \sim 10 / 1)$ afforded 5 as a white solid $(15 \mathrm{~g}, 73 \%)$. m.p. $115-117^{\circ} \mathrm{C}$. ${ }^{1} \mathrm{H}$ NMR $\left(600 \mathrm{MHz}, \mathrm{CDCl}_{3}\right) \delta 4.90(\mathrm{~d}, J=3.0 \mathrm{~Hz}, 1 \mathrm{H}), 3.84-3.91(\mathrm{~m}, 2 \mathrm{H})$, $3.66-3.74(\mathrm{~m}, 2 \mathrm{H}), 3.48(\mathrm{t}, J=9.0 \mathrm{~Hz}, 1 \mathrm{H}), 3.42(\mathrm{dd}, J=3.0,6.0 \mathrm{~Hz}, 1 \mathrm{H}), 1.80$ $(\mathrm{t}, J=6.0 \mathrm{~Hz}, 1 \mathrm{H}), 0.10-0.17(\mathrm{~m}, 27 \mathrm{H})$

\section{Preparation of intermediates $\mathbf{3 n}-\mathbf{s}$}

$2,2^{\prime}, 3,3^{\prime}, 4,4^{\prime}$-Hexa(trimethylsilyl)-6,6'-bis(2,6-dichlorobenzoyl)- $\alpha, \alpha$-D-trehalose (3n). To a stirred solution of 2,6-dichlorobenzoic acid $(210 \mathrm{mg}, 1.1 \mathrm{mmol})$ in anhydrous $\mathrm{CH}_{2} \mathrm{Cl}_{2}(10 \mathrm{ml})$ was added DCC $(227 \mathrm{mg}, 1.1 \mathrm{mmol})$ and DMAP $(135 \mathrm{mg}, 1.1 \mathrm{mmol})$. The mixture was stirred for $15 \mathrm{~min} .2,2^{\prime}, 3,3^{\prime}, 4,4^{\prime}$ hexa(trimethylsilyl)- $\alpha, \alpha$-D-trehalose $(5,388 \mathrm{mg}, 0.5 \mathrm{mmol})$ was added. After stirring for $24 \mathrm{~h}$, the reaction mixture was filtered. The filtrate was concentrated and purified by silica gel chromatography (hexane/ethyl acetate: 20/1) to give 3n as a white solid $(387 \mathrm{mg}, 69 \%)$, m.p. $201-202^{\circ} \mathrm{C} .{ }^{1} \mathrm{H}$ NMR $(600 \mathrm{MHz}$, DMSO- $\left.d_{6}\right) \delta 7.32(\mathrm{~d}, J=1.8 \mathrm{~Hz}, 1 \mathrm{H}), 7.31(\mathrm{~s}, 1 \mathrm{H}), 7.27(\mathrm{dd}, J=6.6,2.4 \mathrm{~Hz}$, $1 \mathrm{H}), 4.93(\mathrm{~d}, J=3.0 \mathrm{~Hz}, 1 \mathrm{H}), 4.60(\mathrm{dd}, J=1.8,9.6 \mathrm{~Hz}, 1 \mathrm{H}), 4.43(\mathrm{dd}, J=6.0$, $5.4 \mathrm{~Hz}, 1 \mathrm{H}), 4.09-4.12(\mathrm{~m}, 1 \mathrm{H}), 3.92(\mathrm{t}, J=9.0 \mathrm{~Hz}, 1 \mathrm{H}), 3.45(\mathrm{t}, J=9.0 \mathrm{~Hz}$, $1 \mathrm{H}), 3.39(\mathrm{dd}, J=3.0,6.0 \mathrm{~Hz}, 1 \mathrm{H}), 0.10-0.15(\mathrm{~m}, 27 \mathrm{H})$; ESI-MS $\mathrm{m} / \mathrm{z} 1119.4$, $1121.4[\mathrm{MH}]^{+}$.

Following the same procedures described for $\mathbf{3 n}$, intermediates $\mathbf{3 o}-\mathbf{s}$ were prepared.

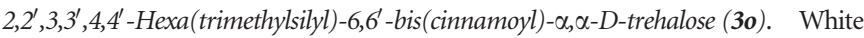
solid; $84 \%$; m.p. $\quad{ }^{138-140{ }^{\circ} \mathrm{C} .} \quad{ }^{1} \mathrm{H} \quad \mathrm{NMR} \quad\left(600 \mathrm{MHz}, \mathrm{CDCl}_{3}\right) \quad \delta \quad 7.71$ $(\mathrm{d}, J=6.6 \mathrm{~Hz}, 1 \mathrm{H}), 7.53$ (s, 2H), $7.39(\mathrm{~s}, 3 \mathrm{H}), 6.50(\mathrm{~d}, J=9.6 \mathrm{~Hz}, 1 \mathrm{H}), 5.00$ $(\mathrm{s}, 1 \mathrm{H}), 4.40(\mathrm{~d}, J=11.4 \mathrm{~Hz}, 1 \mathrm{H}), 4.22(\mathrm{~d}, J=12.0 \mathrm{~Hz}, 1 \mathrm{H}), 4.09(\mathrm{~d}, J=9.6 \mathrm{~Hz}$, $1 \mathrm{H}), 3.95(\mathrm{t}, J=9.0 \mathrm{~Hz}, 1 \mathrm{H}), 3.57(\mathrm{t}, J=9.0 \mathrm{~Hz}, 1 \mathrm{H}), 3.51(\mathrm{~d}, J=9.0 \mathrm{~Hz}, 1 \mathrm{H})$, $0.14-0.17(\mathrm{~m}, 27 \mathrm{H})$; ESI-MS $m / z 1035.7[\mathrm{MH}]^{+}$.

$2,2^{\prime}, 3,3^{\prime}, 4,4^{\prime}$-Hexa(trimethylsilyl)-6,6'-bis(3,4-dimethoxycinnamoyl)- $\alpha, \alpha-D$ trehalose (3p). White solid; 78\%; m.p. $145-147^{\circ} \mathrm{C} .{ }^{1} \mathrm{H}$ NMR $(600 \mathrm{MHz}$, $\left.\mathrm{CDCl}_{3}\right) \delta 7.65(\mathrm{~d}, J=15.6 \mathrm{~Hz}, 1 \mathrm{H}), 7.12(\mathrm{dd}, J=1.8,6.6 \mathrm{~Hz}, 1 \mathrm{H}), 7.06(\mathrm{~d}$, $J=1.8 \mathrm{~Hz}, 3 \mathrm{H}), 6.87(\mathrm{t}, J=8.4 \mathrm{~Hz}, 1 \mathrm{H}), 6.36(\mathrm{~d}, J=10.2 \mathrm{~Hz}, 1 \mathrm{H}), 4.90(\mathrm{~d}$, $J=3.0 \mathrm{~Hz}, 1 \mathrm{H}), 4.40(\mathrm{dd}, J=2.4,8.4 \mathrm{~Hz}, 1 \mathrm{H}), 4.22(\mathrm{dd}, J=3.6,7.8 \mathrm{~Hz}, 1 \mathrm{H})$, $4.097-4.11(\mathrm{~m}, 1 \mathrm{H}), 3.94(\mathrm{~s}, 3 \mathrm{H}), 3.90(\mathrm{~s}, 3 \mathrm{H}), 3.84-3.89(\mathrm{~m}, 1 \mathrm{H}), 3.66-3.74$ (m, 1H), 3.41-3.50 (m, 1H), 0.12-0.16 (m, 27H); ESI-MS m/z $1155.6[\mathrm{MH}]^{+}$.

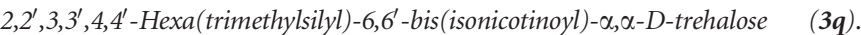
White solid; $78 \%$; m.p. $144-145^{\circ} \mathrm{C} .{ }^{1} \mathrm{H}$ NMR $\left(600 \mathrm{MHz}, \mathrm{CDCl}_{3}\right) \delta 8.81$ (d, $J=5.4 \mathrm{~Hz}, 2 \mathrm{H}), 7.87(\mathrm{~d}, J=6.0 \mathrm{~Hz}, 2 \mathrm{H}), 4.95(\mathrm{~d}, J=3.6 \mathrm{~Hz}, 1 \mathrm{H}), 4.62$ $(\mathrm{dd}, J=2.4,9.6 \mathrm{~Hz}, 1 \mathrm{H}), 4.33(\mathrm{dd}, J=3.6,8.4 \mathrm{~Hz}, 1 \mathrm{H}), 4.11-4.14(\mathrm{~m}, 1 \mathrm{H})$, $3.96(\mathrm{t}, J=9.0 \mathrm{~Hz}, 1 \mathrm{H}), 3.61(\mathrm{t}, J=9.0 \mathrm{~Hz}, 1 \mathrm{H}), 3.48(\mathrm{dd}, J=3.0,6.0 \mathrm{~Hz}, 1 \mathrm{H})$, $0.13-0.18(\mathrm{~m}, 27 \mathrm{H})$; ESI-MS $\mathrm{m} / \mathrm{z} 985.6[\mathrm{MH}]^{+}$.

$2,2^{\prime}, 3,3^{\prime}, 4,4^{\prime}$-Hexa (trimethylsilyl)-6, $6^{\prime}$-bis (pyrazine-2-carbonyl)- $\alpha, \alpha$-D-trehalose (3r). White solid; $85 \%$; m.p. $166-167^{\circ} \mathrm{C} .{ }^{1} \mathrm{H}$ NMR $\left(600 \mathrm{MHz}, \mathrm{CDCl}_{3}\right) \delta 9.30$ (s, $1 \mathrm{H}), 8.75(\mathrm{~d}, J=6.0 \mathrm{~Hz}, 1 \mathrm{H}), 7.27(\mathrm{~s}, 1 \mathrm{H}), 4.96(\mathrm{~d}, J=2.4 \mathrm{~Hz}, 1 \mathrm{H}), 4.64$ $(\mathrm{d}, J=10.4 \mathrm{~Hz}, 1 \mathrm{H}), 4.42(\mathrm{dd}, J=3.6,8.4 \mathrm{~Hz}, 1 \mathrm{H}), 4.14(\mathrm{~d}, J=9.6 \mathrm{~Hz}, 1 \mathrm{H})$, $3.96(\mathrm{t}, J=9.0 \mathrm{~Hz}, 1 \mathrm{H}), 3.66(\mathrm{t}, J=9.0 \mathrm{~Hz}, 1 \mathrm{H}), 3.50(\mathrm{dd}, J=3.0,6.6 \mathrm{~Hz}, 1 \mathrm{H})$, $0.13-0.18(\mathrm{~m}, 27 \mathrm{H})$; ESI-MS $\mathrm{m} / z 987.5[\mathrm{MH}]^{+}$.

2,2',3,3',4,4'-Hexa(trimethylsilyl)-6,6-bis(n-hexanoyl)- $\alpha, \alpha$-D-trehalose (3s). White solid; 89\%; m.p. $72-74^{\circ} \mathrm{C} .{ }^{1} \mathrm{H}$ NMR $\left(600 \mathrm{MHz}, \mathrm{CDCl}_{3}\right) \delta 4.92(\mathrm{~d}, J=3.0 \mathrm{~Hz}$, $1 \mathrm{H}), 4.28(\mathrm{dd}, J=1.2,10.2 \mathrm{~Hz}, 1 \mathrm{H}), 4.06(\mathrm{dd}, J=4.8,7.2 \mathrm{~Hz}, 1 \mathrm{H}), 3.99-4.00$ $(\mathrm{m}, \quad 1 \mathrm{H}), \quad 3.90 \quad(\mathrm{t}, \quad J=9.0 \mathrm{~Hz}, \quad 1 \mathrm{H}), \quad 3.43-3.50 \quad(\mathrm{~m}, \quad 2 \mathrm{H}), \quad 2.32-2.36$ (m, 2H), 1.61-1.64 (m, 2H), 1.31-1.32 (m, 4H), 0.88-0.91 (m, 3H), 0.13-0.16 $(\mathrm{m}, 27 \mathrm{H})$; ESI-MS $m / z$ $971.7[\mathrm{MH}]^{+}$.

\section{Preparation of brartemicin analogs $4 \mathbf{a}-\mathbf{m}$}

6,6-Bis(2-methoxybenzoyl)- $\alpha, \alpha$-D-trehalose (4a). To a solution of $\mathbf{3 a}(240 \mathrm{mg}$, $0.21 \mathrm{mmol})$ in a EtOAc/EtOH $(1: 1)$ solution $(5 \mathrm{ml})$ was added $10 \% \mathrm{Pd} / \mathrm{C}$ $(120 \mathrm{mg})$, and the mixture was stirred at room temperature under an atmosphere of $\mathrm{H}_{2}$ for $18 \mathrm{~h}$. The reaction mixture was filtered through a pad of celite and concentrated under reduced pressure. The residue was purified by silica gel column chromatography $\left(\mathrm{CH}_{2} \mathrm{Cl}_{2} / \mathrm{MeOH}, 15: 1 \sim 6: 1\right)$ to give $4 \mathrm{a}$ $90 \mathrm{mg})$ in $70 \%$ yield as a white solid, m.p. $158-160^{\circ} \mathrm{C},[\alpha]_{\mathrm{D}}^{25}+80.9($ c 4.7, $\mathrm{MeOH}) .{ }^{1} \mathrm{H}$ NMR $\left(600 \mathrm{MHz}, \mathrm{DMSO}-d_{6}\right) \delta 7.67(\mathrm{dd}, J=1.8,7.8 \mathrm{~Hz}, 1 \mathrm{H}), 7.53$ $(\mathrm{td}, J=8.4,1.8 \mathrm{~Hz}, 1 \mathrm{H}), 7.13(\mathrm{~d}, J=8.4 \mathrm{~Hz}, 1 \mathrm{H}), 7.02(\mathrm{t}, J=7.8 \mathrm{~Hz}, 1 \mathrm{H}), 5.15$ $(\mathrm{d}, J=5.4 \mathrm{~Hz}, 1 \mathrm{H}), 4.95(\mathrm{~d}, J=5.4 \mathrm{~Hz}, 1 \mathrm{H}), 4.89(\mathrm{~d}, J=3.6 \mathrm{~Hz}, 1 \mathrm{H}), 4.87$ $(\mathrm{d}, J=6.0 \mathrm{~Hz}, 1 \mathrm{H}), 4.39(\mathrm{~d}, J=2.4 \mathrm{~Hz}, 1 \mathrm{H}), 4.25(\mathrm{dd}, J=5.4,12.0 \mathrm{~Hz}, 1 \mathrm{H})$, 4.02 (ddd, $J=1.8,5.4,7.2 \mathrm{~Hz}, 1 \mathrm{H}), 3.80(\mathrm{~s}, 3 \mathrm{H}), 3.60(\mathrm{td}, J=9.0,4.8 \mathrm{~Hz}, 1 \mathrm{H})$, 3.25-3.32 (m, 2H); ${ }^{13} \mathrm{C}$ NMR $\left(150 \mathrm{MHz}\right.$, DMSO- $\left.d_{6}\right) \delta 165.1,164.4,161.3$, 133.7, 112.2, 105.7, 99.4, 93.9, 73.2, 72.0, 70.3, 56.2; ESI-MS $\mathrm{m} / \mathrm{z} 611.3$ $[\mathrm{MH}]^{+}, 633.4[\mathrm{MNa}]^{+}$.

Following the same procedures described for $4 \mathrm{a}$, analogs $4 \mathrm{~b}-\mathbf{m}$ were prepared.

6,6-Bis(2-methylbenzoyl)- $\alpha, \alpha$-D-trehalose (4b). White solid; 63\%; m.p. $\left.185-187^{\circ} \mathrm{C} ;[\alpha]\right]^{25}+100.0(c 6.8, \mathrm{MeOH}) .{ }^{1} \mathrm{H}$ NMR $\left(600 \mathrm{MHz}\right.$, DMSO- $\left.d_{6}\right)$ $\delta 7.84(\mathrm{~d}, J=7.8 \mathrm{~Hz}, 1 \mathrm{H}), 7.47(\mathrm{t}, J=7.8 \mathrm{~Hz}, 2 \mathrm{H}), 7.32(\mathrm{~d}, J=7.8 \mathrm{~Hz}, 2 \mathrm{H})$, $5.21(\mathrm{~d}, J=5.4 \mathrm{~Hz}, 1 \mathrm{H}), 4.97(\mathrm{~d}, J=4.8 \mathrm{~Hz}, 1 \mathrm{H}), 4.94(\mathrm{~d}, J=6.0 \mathrm{~Hz}, 1 \mathrm{H}), 4.89$ $(\mathrm{d}, J=3.0 \mathrm{~Hz}, 1 \mathrm{H}), 4.43(\mathrm{~d}, J=10.2 \mathrm{~Hz}, 1 \mathrm{H}), 4.28(\mathrm{dd}, J=5.4,11.4 \mathrm{~Hz}, 1 \mathrm{H})$, 4.09 (dd, $J=6.0,11.4 \mathrm{~Hz}, 1 \mathrm{H}), 3.60(\mathrm{td}, J=9.0,5.4 \mathrm{~Hz}, 1 \mathrm{H}), 3.27-3.33$ $(\mathrm{m}, 1 \mathrm{H}), 3.25(\mathrm{td}, J=12.0,5.4 \mathrm{~Hz}, 1 \mathrm{H}), 2.50(\mathrm{~s}, 3 \mathrm{H}) ;{ }^{13} \mathrm{C} \mathrm{NMR}(150 \mathrm{MHz}$, DMSO- $\left.d_{6}\right) \delta 167.3,139.6,132.6,132.1,123.0,126.4,94.3,73.2,71.9,70.7$, 70.2, 64.4, 21.7; ESI-MS $m / z 579.4[\mathrm{MH}]^{+}, 601.4[\mathrm{MNa}]^{+}$.

6,6-Bis(2-hydroxybenzoyl)- $\alpha, \alpha$-D-trehalose (4c). White solid; 65\%; m.p. $118-121^{\circ} \mathrm{C} ;[\alpha]_{\mathrm{D}}^{25}+109(c 4.6, \mathrm{MeOH}) ;{ }^{1} \mathrm{H}$ NMR $\left(600 \mathrm{MHz}\right.$, DMSO- $\left.d_{6}\right) \delta$ $10.34(\mathrm{~s}, 1 \mathrm{H}), 7.80(\mathrm{~d}, J=9.0 \mathrm{~Hz}, 2 \mathrm{H}), 6.85(\mathrm{~d}, J=9.0 \mathrm{~Hz}, 2 \mathrm{H}), 5.18(\mathrm{~d}, J=4.8$ $\mathrm{Hz}, 1 \mathrm{H}), 4.97(\mathrm{~d}, J=4.8 \mathrm{~Hz}, 1 \mathrm{H}), 4.95(\mathrm{~d}, J=5.4 \mathrm{~Hz}, 1 \mathrm{H}), 4.87(\mathrm{~d}, J=3.6 \mathrm{~Hz}$, $1 \mathrm{H}), 4.35(\mathrm{~d}, J=10.2 \mathrm{~Hz}, 1 \mathrm{H}), 4.26(\mathrm{dd}, J=5.4,12.0 \mathrm{~Hz}, 1 \mathrm{H}), 4.08(\mathrm{ddd}, J=1.8$, 7.2, $10.2 \mathrm{~Hz}, 1 \mathrm{H}), 3.60(\mathrm{td}, J=9.0,4.8 \mathrm{~Hz}, 1 \mathrm{H}), 3.27-3.35(\mathrm{~m}, 1 \mathrm{H}), 3.25(\mathrm{td}$, $J=9.0,5.4 \mathrm{~Hz}, 1 \mathrm{H}) ;{ }^{13} \mathrm{C}$ NMR $\left(150 \mathrm{MHz}, \mathrm{DMSO}-d_{6}\right) \delta 166.0,162.4,131.9,120.8$, 115.8, 94.3, 73.3, 71.9, 70.6, 70.3, 64.0; ESI-MS $m / z 583.3[\mathrm{MH}]^{+}, 605.3[\mathrm{MNa}]^{+}$.

6,6-Bis(4-methoxybenzoyl)- $\alpha, \alpha$-D-trehalose (4d). White solid; 70\%; m.p. 200-202 ${ }^{\circ} \mathrm{C} ;[\alpha]_{\mathrm{D}}^{25}+79.6(c 4.9, \mathrm{MeOH}) .{ }^{1} \mathrm{H}$ NMR $\left(600 \mathrm{MHz}\right.$, DMSO- $\left.d_{6}\right) \delta$ $7.92(\mathrm{dd}, J=1.8,9.0 \mathrm{~Hz}, 2 \mathrm{H}), 7.05(\mathrm{dd}, J=1.8,9.0 \mathrm{~Hz}, 2 \mathrm{H}), 5.20(\mathrm{~d}, J=5.4 \mathrm{~Hz}$, $1 \mathrm{H}), 4.98(\mathrm{~d}, J=4.8 \mathrm{~Hz}, 1 \mathrm{H}), 4.95(\mathrm{~d}, J=6.0 \mathrm{~Hz}, 1 \mathrm{H}), 4.88(\mathrm{~d}, J=3.6 \mathrm{~Hz}, 1 \mathrm{H})$, $4.39(\mathrm{dd}, J=1.8,12.0 \mathrm{~Hz}, 1 \mathrm{H}), 4.28(\mathrm{dd}, J=5.4,12.0 \mathrm{~Hz}, 1 \mathrm{H}), 4.08-4.12(\mathrm{~m}$, $1 \mathrm{H}) 3.83(\mathrm{~s}, 3 \mathrm{H}), 3.60(\mathrm{td}, J=9.0,5.4 \mathrm{~Hz}, 1 \mathrm{H}), 3.26-3.36(\mathrm{~m}, 1 \mathrm{H}), 3.26(\mathrm{td}$, $J=9.0,5.4 \mathrm{~Hz}, 1 \mathrm{H}) ;{ }^{13} \mathrm{C}$ NMR $\left(150 \mathrm{MHz}, \mathrm{DMSO}-d_{6}\right) \delta 165.8,163.6,131.7$, $122.5,114.5,94.3,73.3,71.9,70.6,70.3,64.2,55.9$; ESI-MS $m / z$ 611.4 $[\mathrm{MH}]^{+}$, $633.4[\mathrm{MNa}]^{+}$.

6,6'-Bis(4-hydroxybenzoyl)- $\alpha, \alpha$-D-trehalose (4e). White solid; 65\%; m.p. $119-121^{\circ} \mathrm{C} ;[\alpha]_{\mathrm{D}}^{25}+56.5(c 4.6, \mathrm{MeOH}) .{ }^{1} \mathrm{H}$ NMR $\left(600 \mathrm{MHz}, \mathrm{DMSO}-d_{6}\right) \delta$ $10.34(\mathrm{~s}, 1 \mathrm{H}), 7.80(\mathrm{~d}, J=9.0 \mathrm{~Hz}, 2 \mathrm{H}), 6.85(\mathrm{~d}, J=9.0 \mathrm{~Hz}, 2 \mathrm{H}), 5.18$ (d, $J=4.8 \mathrm{~Hz}, 1 \mathrm{H}), 4.97(\mathrm{~d}, J=4.8 \mathrm{~Hz}, 1 \mathrm{H}), 4.95(\mathrm{~d}, J=5.4 \mathrm{~Hz}, 1 \mathrm{H}), 4.87$ (d, $J=3.6 \mathrm{~Hz}, 1 \mathrm{H}), 4.35$ (d, $J=10.2 \mathrm{~Hz}, 1 \mathrm{H}), 4.26(\mathrm{dd}, J=5.4,12.0 \mathrm{~Hz}, 1 \mathrm{H})$, 4.08 (ddd, $J=1.8,7.2,10.2 \mathrm{~Hz}, 1 \mathrm{H}), 3.60(\mathrm{td}, J=9.0,4.8 \mathrm{~Hz}, 1 \mathrm{H}), 3.27-3.35$ $(\mathrm{m}, 1 \mathrm{H}), 3.25(\mathrm{td}, J=9.0,5.4 \mathrm{~Hz}, 1 \mathrm{H}) ;{ }^{13} \mathrm{C}$ NMR $\left(150 \mathrm{MHz}, \mathrm{DMSO}-d_{6}\right) \delta$ $166.0,162.4,131.9,120.8,115.8,94.3,73.3,71.9,70.6,70.3,64.0$; ESI-MS $m / z$ $583.3[\mathrm{MH}]^{+}, 605.3[\mathrm{MNa}]^{+}$.

6,6'-Bis(2,3-dimethoxybenzoyl)- $\alpha, \alpha$-D-trehalose (4f). White solid; 60\%; m.p. $135-137^{\circ} \mathrm{C} ;[\alpha]_{\mathrm{D}}^{25}+78.3($ c $6.0, \mathrm{MeOH}) .{ }^{1} \mathrm{H}$ NMR $(600 \mathrm{MHz}$, DMSO$\left.\mathrm{d}_{6}\right) \delta 7.25(\mathrm{~d}, J=7.8 \mathrm{~Hz}, 1 \mathrm{H}), 7.20(\mathrm{~d}, J=7.8 \mathrm{~Hz}, 1 \mathrm{H}), 7.15(\mathrm{t}, J=7.8 \mathrm{~Hz}, 1 \mathrm{H})$, $5.18(\mathrm{~d}, J=5.4 \mathrm{~Hz}, 1 \mathrm{H}), 4.94(\mathrm{~d}, J=4.8 \mathrm{~Hz}, 1 \mathrm{H}), 4.87-4.89(\mathrm{~m}, 2 \mathrm{H}), 4.40$ (d, $J=10.8 \mathrm{~Hz}, 1 \mathrm{H}), 4.30(\mathrm{dd}, J=4.8,11.4 \mathrm{~Hz}, 1 \mathrm{H}), 4.00-4.08(\mathrm{~m}, 1 \mathrm{H}), 3.83$ $(\mathrm{s}, 3 \mathrm{H}), 3.74(\mathrm{~s}, 3 \mathrm{H}), 3.60(\mathrm{td}, J=9.0,4.8 \mathrm{~Hz}, 1 \mathrm{H}), 3.23-3.30(\mathrm{~m}, 2 \mathrm{H})$; ${ }^{13} \mathrm{C}-\mathrm{NMR}\left(150 \mathrm{MHz}\right.$, DMSO- $\left.d_{6}\right) \delta 166.2,153.6,148.4,126.5,124.6,121.8$, 116.7, 94.1, 73.2, 71.90 70.5, 70.2, 64.5, 61.4, 56.4; ESI-MS $m / z$ 671.4 [MH] ${ }^{+}$, $693.4[\mathrm{MNa}]^{+}$. 
6,6'-Bis(2-hydroxy-3-methoxybenzoyl)- $\alpha, \alpha$-D-trehalose (4g). White solid; $70 \%$ m.p. $124-125^{\circ} \mathrm{C} ;[\alpha]_{\mathrm{D}}^{25}+76.3(c 5.9, \mathrm{MeOH}) .{ }^{1} \mathrm{H}$ NMR $\left(600 \mathrm{MHz}, \mathrm{DMSO}-d_{6}\right)$ $\delta 10.51(\mathrm{~s}, 1 \mathrm{H}), 7.38(\mathrm{dd}, J=1.2,6.6 \mathrm{~Hz}, 1 \mathrm{H}), 7.23(\mathrm{dd}, J=1.2,7.2 \mathrm{~Hz}, 1 \mathrm{H})$, $6.90(\mathrm{t}, J=7.8 \mathrm{~Hz}, 1 \mathrm{H}), 5.25(\mathrm{~d}, J=5.4 \mathrm{~Hz}, 1 \mathrm{H}), 4.97(\mathrm{dd}, J=4.8,3.6 \mathrm{~Hz}, 2 \mathrm{H})$, $4.89(\mathrm{~d}, J=3.6 \mathrm{~Hz}, 1 \mathrm{H}), 4.48(\mathrm{~d}, J=1.8 \mathrm{~Hz}, 1 \mathrm{H}), 4.39(\mathrm{dd}, J=5.4,6.0 \mathrm{~Hz}, 1 \mathrm{H})$, $4.10-4.14(\mathrm{~m}, 1 \mathrm{H}), 3.80(\mathrm{~s}, 3 \mathrm{H}), 3.57-3.62(\mathrm{~m}, 1 \mathrm{H}), 3.31-3.35(\mathrm{~m}, 1 \mathrm{H}), 3.24$ $3.29(\mathrm{~m}, 1 \mathrm{H}) ;{ }^{13} \mathrm{C}-\mathrm{NMR}\left(150 \mathrm{MHz}, \mathrm{DMSO}-d_{6}\right) \delta 175.2,175.2,163.1,148.1$, $144.9,143.9,143.9,94.5,72.8,72.7,72.5,70.5,25.7$; ESI-MS $m / z 643.6$ $[\mathrm{MH}]^{+}, 665.6[\mathrm{MNa}]^{+}$.

6,6'-Bis(2,4-dimethoxybenzoyl)- $\alpha, \alpha$-D-trehalose (4h). White solid; 62\%; m.p. 124-125 ${ }^{\circ} \mathrm{C} ;[\alpha]_{\mathrm{D}}^{25}+60.0(c 4.0, \mathrm{MeOH}) .{ }^{1} \mathrm{H}$ NMR $\left(600 \mathrm{MHz}, \mathrm{DMSO}-d_{6}\right) \delta$ $7.73(\mathrm{~d}, J=8.4 \mathrm{~Hz}, 1 \mathrm{H}), 6.58-6.62(\mathrm{~m}, 2 \mathrm{H}), 5.11(\mathrm{~d}, J=6.0 \mathrm{~Hz}, 1 \mathrm{H}), 4.93(\mathrm{~d}$, $J=4.2 \mathrm{~Hz}, 1 \mathrm{H}), 4.90(\mathrm{~d}, J=3.6 \mathrm{~Hz}, 1 \mathrm{H}), 4.83(\mathrm{~d}, J=6.0 \mathrm{~Hz}, 1 \mathrm{H}), 4.33(\mathrm{~d}$, $J=10.2 \mathrm{~Hz}, 1 \mathrm{H}), 4.20(\mathrm{dd}, J=5.4,6.0 \mathrm{~Hz}, 1 \mathrm{H}), 4.00-4.03(\mathrm{~m}, 1 \mathrm{H}), 3.82(\mathrm{~s}$, $3 \mathrm{H}), 3.80(\mathrm{~s}, 3 \mathrm{H}), 3.59-3.63(\mathrm{~m}, 1 \mathrm{H}), 3.28-3.34(\mathrm{~m}, 1 \mathrm{H}), 3.25-3.27(\mathrm{~m}, 1 \mathrm{H})$; ${ }^{13} \mathrm{C}$ NMR $\left(150 \mathrm{MHz}, \mathrm{DMSO}-d_{6}\right) \delta 169.1,160.6,136.2,130.5,112.0,117.8$, $113.3,94.4,73.2,71.9,70.5,70.0,64.9$; ESI-MS $m / z 671.6[\mathrm{MH}]^{+}$.

6,6'-Bis(2,4-dihydroxybenzoyl)- $\alpha, \alpha$-D-trehalose (4i). White solid; 71\%; m.p. $125-126^{\circ} \mathrm{C} ;[\alpha]_{\mathrm{D}}^{25}+56.7(c 6.7, \mathrm{MeOH}) .{ }^{1} \mathrm{H}$ NMR $\left(600 \mathrm{MHz}, \mathrm{DMSO}-d_{6}\right): \delta$ $10.67(\mathrm{~s}, 1 \mathrm{H}), 10.45(\mathrm{~s}, 1 \mathrm{H}), 7.66(\mathrm{~d}, J=9.0 \mathrm{~Hz}, 1 \mathrm{H}), 6.38-6.41(\mathrm{~m}, 1 \mathrm{H}), 6.30$ $(\mathrm{d}, J=1.8 \mathrm{~Hz}, 1 \mathrm{H}), 5.20(\mathrm{~d}, J=5.4 \mathrm{~Hz}, 1 \mathrm{H}), 4.94(\mathrm{dd}, J=4.8,6.0 \mathrm{~Hz}, 2 \mathrm{H}), 4.87$ $(\mathrm{d}, J=3.6 \mathrm{~Hz}, 1 \mathrm{H}), 4.41(\mathrm{~d}, J=10.2 \mathrm{~Hz}, 1 \mathrm{H}), 4.34(\mathrm{dd}, J=5.4,6.0 \mathrm{~Hz}, 1 \mathrm{H})$ $4.08-4.12(\mathrm{~m}, 1 \mathrm{H}), 3.57-3.61(\mathrm{~m}, 1 \mathrm{H}), 3.25-3.35(\mathrm{~m}, 2 \mathrm{H}) ;{ }^{13} \mathrm{C} \quad \mathrm{NMR}$ $\left(150 \mathrm{MHz}, \mathrm{DMSO}-d_{6}\right) \delta 169.5,164.7,163.2,132.2,108.9,104.5,102.9,94.4$, 73.2, 71.9, 70.5, 70.1, 64.4; ESI-MS $m / z 615.5[\mathrm{MH}]{ }^{+}$.

6,6'-Bis(2,4-difluorobenzoyl)- $\alpha, \alpha$-D-trehalose (4j). White solid; 66\%; m.p. $205-207{ }^{\circ} \mathrm{C} ;[\alpha]_{\mathrm{D}}^{25}+67.3($ c 4.9, MeOH$) ;{ }^{1} \mathrm{H}$ NMR $\left(600 \mathrm{MHz}\right.$, DMSO- $\left.d_{6}\right) \delta$ $7.65(\mathrm{td}, J=8.4,1.8 \mathrm{~Hz}, 1 \mathrm{H}), 7.25(\mathrm{t}, J=8.4 \mathrm{~Hz}, 2 \mathrm{H}), 5.23(\mathrm{~d}, J=4.2 \mathrm{~Hz}, 1 \mathrm{H})$, $5.05(\mathrm{~s}, 1 \mathrm{H}), 4.87(\mathrm{~d}, J=3.6 \mathrm{~Hz}, 2 \mathrm{H}), 4.50(\mathrm{dd}, J=1.8,11.4 \mathrm{~Hz}, 1 \mathrm{H}), 4.38(\mathrm{dd}$, $J=4.8,11.4 \mathrm{~Hz}, 1 \mathrm{H}), 4.02(\mathrm{ddd}, J=1.8,4.8,9.6 \mathrm{~Hz}, 1 \mathrm{H}), 3.59(\mathrm{t}, J=9.6 \mathrm{~Hz}$, $1 \mathrm{H}), \quad 3.21-3.26(\mathrm{~m}, 2 \mathrm{H}) ;{ }^{13} \mathrm{C}$ NMR $\left(150 \mathrm{MHz}, \mathrm{DMSO}-d_{6}\right) \delta 160.9$, $150.9,141.3,133.5,120.1,115.4,110.5,95.6,65.1,39.1,23.4,15.1$; ESI-MS $\mathrm{m} / z 623.2[\mathrm{MH}]^{+}$.

6,6'-Bis(2-ethylamino-6-methylbenzoyl)- $\alpha, \alpha$-D-trehalose (4k). White solid; $36 \%$; m.p. $101-103^{\circ} \mathrm{C} ;[\alpha]_{\mathrm{D}}^{25}+66.7$ (c $\left.1.5, \mathrm{MeOH}\right) .{ }^{1} \mathrm{H}$ NMR $(600 \mathrm{MHz}$, DMSO- $\left.d_{6}\right) \delta 7.16(\mathrm{t}, J=8.4 \mathrm{~Hz}, 1 \mathrm{H}), 6.54(\mathrm{~d}, J=8.4 \mathrm{~Hz}, 1 \mathrm{H}), 6.45(\mathrm{~d}, J=8.4$ $\mathrm{Hz}, 1 \mathrm{H}), 6.19(\mathrm{~s}, 1 \mathrm{H}), 5.20(\mathrm{~d}, J=5.4 \mathrm{~Hz}, 1 \mathrm{H}), 4.91-4.93(\mathrm{~m}, 3 \mathrm{H}), 4.45(\mathrm{~d}$, $J=10.8 \mathrm{~Hz}, 1 \mathrm{H}), 4.26(\mathrm{dd}, J=4.8,11.4 \mathrm{~Hz}, 1 \mathrm{H}), 4.04-4.07(\mathrm{~m}, 1 \mathrm{H}), 3.57-3.60$ $(\mathrm{m}, 1 \mathrm{H}), 3.26-3.32(\mathrm{~m}, 1 \mathrm{H}), 3.19-3.28(\mathrm{~m}, 1 \mathrm{H}), 3.06-3.13(\mathrm{~m}, 2 \mathrm{H}), 2.32$ $(\mathrm{s}, 3 \mathrm{H}), 1.15$ (t, $J=7.2 \mathrm{~Hz}, 3 \mathrm{H}) ;{ }^{13} \mathrm{C}$ NMR $\left(100 \mathrm{MHz}, \mathrm{CD}_{3} \mathrm{OD}\right) \delta 170.9,150.9$, $141.3,133.5,120.1,115.4,110.5,95.6,74.7,73.3,72.4,71.5,65.1,39.1,23.4$, 15.1; ESI-MS $m / z 665.3[\mathrm{MH}]^{+}$.

6,6'-Bis(4-fluoro-3-methoxybenzoyl)- $\alpha, \alpha$-D-trehalose (4l). White solid; $82 \%$; m.p. $210-212^{\circ} \mathrm{C} ;[\alpha]_{\mathrm{D}}^{25}+82.1\left(\right.$ c 6.7, MeOH). ${ }^{1} \mathrm{H}$ NMR $(600 \mathrm{MHz}$, DMSO$\left.d_{6}\right) \delta 7.63(\mathrm{~d}, J=7.8 \mathrm{~Hz}, 1 \mathrm{H}), 7.58-7.61(\mathrm{~m}, 1 \mathrm{H}), 7.38(\mathrm{dd}, J=8.4,10.8 \mathrm{~Hz}$, $1 \mathrm{H}), 5.24(\mathrm{~d}, J=4.8 \mathrm{~Hz}, 1 \mathrm{H}), 5.00(\mathrm{dd}, J=5.4,6.0 \mathrm{~Hz}, 2 \mathrm{H}), 4.90(\mathrm{~d}, 24=3.6$ $\mathrm{Hz}, 1 \mathrm{H}), 4.44(\mathrm{~d}, J=10.2 \mathrm{~Hz}, 1 \mathrm{H}), 4.30(\mathrm{dd}, J=6.6,11.4 \mathrm{~Hz}, 1 \mathrm{H}), 4.12(\mathrm{t}$, $J=9.0 \mathrm{~Hz}, 1 \mathrm{H}) 3.89(\mathrm{~s}, 3 \mathrm{H}), 3.60(\mathrm{td}, J=9.0,5.4 \mathrm{~Hz}, 1 \mathrm{H}), 3.28-3.35(\mathrm{~m}, 1 \mathrm{H})$, $3.23(\mathrm{td}, J=9.0,5.4 \mathrm{~Hz}, 1 \mathrm{H}) ;{ }^{13} \mathrm{C}$ NMR $\left(150 \mathrm{MHz}, \mathrm{DMSO}-d_{6}\right) \delta 164.7,153.6$, 147.1, 126.5, 122,.6, 116.2, 114.0, 93.7, 72.7, 71.4, 70.2, 69.8, 64.4, 55.9; ESI-MS $\mathrm{m} / \mathrm{z} 647.2[\mathrm{MH}]^{+}, 669.3[\mathrm{MNa}]^{+}$.

6,6'-Bis(3,4,5-trimethoxybenzoyl)- $\alpha, \alpha$-D-trehalose (4m). White solid; 59\%; m.p. $140-142^{\circ} \mathrm{C} ;[\alpha]_{\mathrm{D}}^{25}+58.0($ c $5.0, \mathrm{MeOH}) ;{ }^{1} \mathrm{H}$ NMR $(600 \mathrm{MHz}$, DMSO$\left.d_{6}\right) \delta 7.23(\mathrm{~s}, 2 \mathrm{H}), 5.25(\mathrm{~d}, J=6.0 \mathrm{~Hz}, 1 \mathrm{H}), 5.00(\mathrm{~d}, J=4.8 \mathrm{~Hz}, 1 \mathrm{H}), 4.94-4.97$ $(\mathrm{m}, 2 \mathrm{H}), 4.44(\mathrm{~d}, J=9.6 \mathrm{~Hz}, 1 \mathrm{H}), 4.26(\mathrm{dd}, J=7.2,11.4 \mathrm{~Hz}, 1 \mathrm{H}), 4.11(\mathrm{t}$, $J=9.6 \mathrm{~Hz}, 1 \mathrm{H}) 3.81(\mathrm{~s}, 6 \mathrm{H}), 3.73(\mathrm{~s}, 3 \mathrm{H}), 3.62(\mathrm{td}, J=9.0,4.8 \mathrm{~Hz}, 1 \mathrm{H}), 3.29$ $(\mathrm{td}, J=9.0,6.0 \mathrm{~Hz}, 1 \mathrm{H}), 3.19(\mathrm{td}, J=9.0,4.8 \mathrm{~Hz}, 1 \mathrm{H}) ;{ }^{13} \mathrm{C} \mathrm{NMR}(150 \mathrm{MHz}$, DMSO- $\left.d_{6}\right) \delta 167.0,151.4,149.4,145.3,127.3,123.6,115.9,111.9,110.7,94.2$, 73.2, 71.9, 70.4, 70.2, 63.7, 56.1, 56.0; ESI-MS $m / z 731.3[\mathrm{MH}]^{+}, 753.5$ $[\mathrm{MNa}]^{+}$.

\section{Preparation of brartemicin analogs $4 \mathrm{n}-\mathrm{s}$}

$6,6^{\prime}$-Bis(2-methoxybenzoyl)- $\alpha, \alpha$-D-trehalose (4n). To a stirred solution of $\mathbf{3 n}$ $(135 \mathrm{mg}, 0.12 \mathrm{mmol})$ in $\mathrm{MeOH}(15)$ and water $(3 \mathrm{ml})$ was added one drop of acetic acid and the mixture was refluxed for $3 \mathrm{~h}$. After removing the solvent, the residue was purified by silica gel column chromatography $\left(\mathrm{CH}_{2} \mathrm{Cl}_{2} / \mathrm{MeOH}\right.$, $15 \sim 6: 1)$ to give $4 \mathrm{n}(51 \mathrm{mg})$ in $62 \%$ yield as a white solid, m.p. $193-194{ }^{\circ} \mathrm{C}$; $[\alpha]_{\mathrm{D}}^{25}+74.6$ (c 6.3, DMF). ${ }^{1} \mathrm{H}$ NMR $\left(600 \mathrm{MHz}\right.$, DMSO- $\left.d_{6}\right) \delta 7.58$ $(\mathrm{d}, J=7.8 \mathrm{~Hz}, 2 \mathrm{H}), 7.53(\mathrm{dd}, J=6.6,9.0 \mathrm{~Hz}, 1 \mathrm{H}), 5.19(\mathrm{~d}, J=5.4 \mathrm{~Hz}, 1 \mathrm{H})$, $4.95(\mathrm{~d}, J=4.2 \mathrm{~Hz}, 1 \mathrm{H}), 4.88(\mathrm{~d}, J=3.6 \mathrm{~Hz}, 1 \mathrm{H}), 4.81(\mathrm{~d}, J=6.0 \mathrm{~Hz}, 1 \mathrm{H}), 4.56$ $(\mathrm{d}, J=10.2 \mathrm{~Hz}, 1 \mathrm{H}), 4.43(\mathrm{dd}, J=4.8,6.6 \mathrm{~Hz}, 1 \mathrm{H}), 3.98-4.01(\mathrm{dd}, J=3.6$, $6.6 \mathrm{~Hz}, 1 \mathrm{H}), 3.56-3.60(\mathrm{~m}, 1 \mathrm{H}), 3.16-3.26(\mathrm{~m}, 2 \mathrm{H}) ;{ }^{13} \mathrm{C} \mathrm{NMR}(150 \mathrm{MHz}$, DMSO- $\left.d_{6}\right) \delta 164.4,133.4,132.7,131.1,128.8,93.9,73.1,71.8,70.3,70.1,65.5$; ESI-MS $m / z 689.3[\mathrm{MH}]^{+}$.

Following the same procedures described for $4 \mathbf{n}$, analogs $4 \mathbf{0}-\mathbf{s}$ were prepared.

6,6 ${ }^{\prime}$-Bis (cinnamoyl)- $\alpha, \alpha$-D-trehalose (4o). White solid; $86 \%$; m.p. $135-136{ }^{\circ} \mathrm{C}$; $[\alpha]_{\mathrm{D}}^{25}+66.7$ (c 4.5, DMF). ${ }^{1} \mathrm{H}$ NMR $\left(600 \mathrm{MHz}, \mathrm{DMSO}-d_{6}\right) \delta 7.72(\mathrm{dd}, J=1.8$, $4.2 \mathrm{~Hz}, 2 \mathrm{H}), 7.65(\mathrm{~d}, J=16.2 \mathrm{~Hz}, 1 \mathrm{H}), 7.42(\mathrm{dd}, J=3.6,8.4 \mathrm{~Hz}, 3 \mathrm{H}), 7.64(\mathrm{~d}$, $J=15.6 \mathrm{~Hz}, \quad 1 \mathrm{H}), \quad 5.16 \quad(\mathrm{~d}, \quad J=4.8 \mathrm{~Hz}, \quad 1 \mathrm{H}), \quad 4.97 \quad(\mathrm{~s}, \quad 1 \mathrm{H}), \quad 4.90$ $(\mathrm{t}, J=3.0 \mathrm{~Hz}, 2 \mathrm{H}), 4.32(\mathrm{~d}, J=4.2 \mathrm{~Hz}, 1 \mathrm{H}), 4.22(\mathrm{dd}, J=5.4,6.6 \mathrm{~Hz}, 1 \mathrm{H})$, $4.02(\mathrm{dd}, J=5.4,4.2 \mathrm{~Hz}, 1 \mathrm{H}), 3.59(\mathrm{t}, J=9.0 \mathrm{~Hz}, 1 \mathrm{H}), 3.31-3.34(\mathrm{~m}, 1 \mathrm{H})$, 3.19-3.24 (m, 1H); ${ }^{13} \mathrm{C}$ NMR (150 MHz, DMSO- $\left.d_{6}\right) \delta 166.7,145.0,134.5$, $130.9,129.4,128.9,112.0,118.5,94.2,73.3,71.9,70.5,70.2,64.0$; ESI-MS $m / z$ $603.6[\mathrm{MH}]^{+}$.

6,6'-Bis(3,4-dimethoxycinnamoyl)- $\alpha, \alpha$-D-trehalose (4p). White solid; $83 \%$; m.p. $\quad 216-218^{\circ} \mathrm{C} ; \quad[\alpha]_{\mathrm{D}}^{25}+77.6$ (c $\left.5.8, \quad \mathrm{DMF}\right) .{ }^{1} \mathrm{H} \quad \mathrm{NMR} \quad(600 \mathrm{MHz}$, DMSO- $\left.d_{6}\right) \delta 7.58(\mathrm{~d}, J=15.6 \mathrm{~Hz}, 1 \mathrm{H}), 7.35(\mathrm{~d}, J=1.8 \mathrm{~Hz}, 1 \mathrm{H}), 7.22$ $(\mathrm{dd}, J=1.2,6.6 \mathrm{~Hz}, 1 \mathrm{H}), 6.97(\mathrm{~d}, J=8.4 \mathrm{~Hz}, 1 \mathrm{H}), 6.55(\mathrm{~d}, J=15.6 \mathrm{~Hz}, 1 \mathrm{H})$, $5.12(\mathrm{~d}, J=5.4 \mathrm{~Hz}, 1 \mathrm{H}), 4.94(\mathrm{~d}, J=5.4 \mathrm{~Hz}, 1 \mathrm{H}), 4.89(\mathrm{~d}, J=3.6 \mathrm{~Hz}, 1 \mathrm{H}), 4.87$ $(\mathrm{d}, J=6.0 \mathrm{~Hz}, 1 \mathrm{H}), 4.30(\mathrm{~d}, J=12.0 \mathrm{~Hz}, 1 \mathrm{H}), 4.22(\mathrm{dd}, J=5.4,6.6 \mathrm{~Hz}, 1 \mathrm{H})$, $3.99-4.02(\mathrm{~m}, 1 \mathrm{H}), 3.80(\mathrm{~s}, 3 \mathrm{H}), 3.75(\mathrm{~s}, 3 \mathrm{H}), 3.57-3.61(\mathrm{~m}, 1 \mathrm{H}), 3.30-3.33$ $(\mathrm{m}, 1 \mathrm{H}), 3.21-3.25(\mathrm{~m}, 1 \mathrm{H}) ;{ }^{13} \mathrm{C}$ NMR $\left(150 \mathrm{MHz}, \mathrm{DMSO}-d_{6}\right) \delta 182.5,163.4$, 161.6, 157.4, 128.9, 123.1, 115.2, 105.9, 101.0, 100.3, 95.2, 71.2, 70.8, 68.8, 66.6, 56.0; ESI-MS $m / z 723.7[\mathrm{MH}]^{+}$.

6,6'-Bis(isonicotinoyl)- $\alpha, \alpha$-D-trehalose (4q). White solid; 71\%; m.p. $190-191{ }^{\circ} \mathrm{C} ;[\alpha]_{\mathrm{D}}^{25}+90.0(c 5.0, \mathrm{MeOH}) .{ }^{1} \mathrm{H}$ NMR $\left(600 \mathrm{MHz}, \mathrm{DMSO}-d_{6}\right) \delta$ $8.81(\mathrm{~d}, J=4.2 \mathrm{~Hz}, 2 \mathrm{H}), 7.83(\mathrm{~d}, J=4.2 \mathrm{~Hz}, 2 \mathrm{H}), 5.26(\mathrm{~s}, 1 \mathrm{H}), 5.04(\mathrm{~s}, 2 \mathrm{H})$, $4.87(\mathrm{~d}, J=3.0 \mathrm{~Hz}, 1 \mathrm{H}), 4.48(\mathrm{~d}, J=5.4 \mathrm{~Hz}, 1 \mathrm{H}), 4.38(\mathrm{dd}, J=5.4,6.0 \mathrm{~Hz}, 1 \mathrm{H})$, $4.14(\mathrm{t}, J=6.6 \mathrm{~Hz}, 1 \mathrm{H}), 3.60(\mathrm{t}, J=9.0 \mathrm{~Hz}, 1 \mathrm{H}), 3.30-3.34(\mathrm{~m}, 1 \mathrm{H}), 3.26$ $(\mathrm{t}, J=9.6 \mathrm{~Hz}, 2 \mathrm{H}) ;{ }^{13} \mathrm{C}$ NMR $\left(150 \mathrm{MHz}\right.$, DMSO- $\left.d_{6}\right) \delta 165.0 .151 .3,137.4$, 123.0, 94.6, 73.2, 71.8, 70.5, 70.2, 65.3; ESI-MS $m / z 653.5[\mathrm{MH}]^{+}$.

6,6'-Bis(pyrazine-2-carbonyl)- $\alpha, \alpha$-D-trehalose (4r). White solid; 67\%; m.p. $64-65^{\circ} \mathrm{C} ;[\alpha]_{\mathrm{D}}^{25}+84.7\left(c 5.9, \mathrm{H}_{2} \mathrm{O}\right) .{ }^{1} \mathrm{H}$ NMR $\left(600 \mathrm{MHz}\right.$, DMSO- $\left.d_{6}\right) \delta 9.20$ $(\mathrm{d}, J=1.2 \mathrm{~Hz}, 1 \mathrm{H}), 8.90(\mathrm{~d}, J=2.4 \mathrm{~Hz}, 1 \mathrm{H}), 8.84(\mathrm{t}, J=1.8 \mathrm{~Hz}, 1 \mathrm{H}), 5.23(\mathrm{~d}$, $J=5.4 \mathrm{~Hz}, 1 \mathrm{H}), 4.94(\mathrm{dd}, J=4.8,7.2 \mathrm{~Hz}, 2 \mathrm{H}), 4.89(\mathrm{~d}, J=3.6 \mathrm{~Hz}, 1 \mathrm{H})$, $4.55(\mathrm{~d}, J=10.2 \mathrm{~Hz}, 1 \mathrm{H}), 4.41(\mathrm{dd}, J=4.8,6.6 \mathrm{~Hz}, 1 \mathrm{H}), 4.10-4.14(\mathrm{~m}, 1 \mathrm{H})$, $3.57-3.62(\mathrm{~m}, 1 \mathrm{H}), 3.28-3.34(\mathrm{~m}, 1 \mathrm{H}), 3.17(\mathrm{t}, J=5.4 \mathrm{~Hz}, 1 \mathrm{H}) ;{ }^{13} \mathrm{C} \mathrm{NMR}$ $\left(150 \mathrm{MHz}, \mathrm{DMSO}-d_{6}\right) \delta 165.9,158.8,134.1,131.4,120.5,120.4,113.0,93.9$, 73.2, 71.9, 70.5, 70.2, 64.2, 56.1; ESI-MS $m / z 555.5[\mathrm{MH}]^{+}$.

6,6'-Bis(n-hexanoyl)- $\alpha, \alpha$-D-trehalose (4s). White solid; $91 \%$; m.p. $155-156^{\circ} \mathrm{C}$; $[\alpha]_{\mathrm{D}}^{25}+97.1$ (c 6.8, MeOH). ${ }^{1} \mathrm{H}$ NMR $\left(600 \mathrm{MHz}\right.$, DMSO- $\left.d_{6}\right) \delta 5.08$ $(\mathrm{d}, J=5.4 \mathrm{~Hz}, 1 \mathrm{H}), 4.90(\mathrm{~d}, J=4.8 \mathrm{~Hz}, 1 \mathrm{H}), 4.82(\mathrm{dd}, J=3.6,7.0 \mathrm{~Hz}, 1 \mathrm{H})$, $4.79(\mathrm{~d}, J=6.0 \mathrm{~Hz}, 1 \mathrm{H}), 4.23(\mathrm{~d}, J=5.4 \mathrm{~Hz}, 1 \mathrm{H}), 4.04(\mathrm{dd}, J=5.4,6.0 \mathrm{~Hz}, 1 \mathrm{H})$, $3.89(\mathrm{dd}, J=4.8,5.4 \mathrm{~Hz}, 1 \mathrm{H}), 3.51-3.56(\mathrm{~m}, 1 \mathrm{H}), 3.23-3.33(\mathrm{~m}, 1 \mathrm{H}), 3.10-3.15$ $(\mathrm{m}, 1 \mathrm{H}), 2.27(\mathrm{t}, J=7.2 \mathrm{~Hz}, 2 \mathrm{H}), 1.49-1.54(\mathrm{~m}, 2 \mathrm{H}), 1.23-1.29(\mathrm{~m}, 4 \mathrm{H})$, $0.84-0.87(\mathrm{~m}, 3 \mathrm{H}) ;{ }^{13} \mathrm{C}$ NMR (150 MHz, DMSO- $\left.d_{6}\right) \delta 173.3,93.9,73.2,71.9$, 70.5, 70.2, 63.5, 34.0, 31.1, 24.6, 22.3, 14.2; ESI-MS $m / z$ 553.6 $[\mathrm{MH}]^{+}$.

\section{Biological activity}

Cytotoxicity assay. Murine colon 26-L5 carcinoma cells were suspended $(1 \times$ $10^{5}$ cells per ml) in RPMI medium containing $10 \%$ FCS, L-glutamine and the test compound dissolved in DMSO at various concentrations, and seeded into 
the wells of a 96-well culture plate $\left(1 \times 10^{4}\right.$ cells per $100 \mu$ l per well $)$. After incubation for $24 \mathrm{~h}$ in a humidified $5 \% \mathrm{CO}_{2}$ incubator at $37^{\circ} \mathrm{C}$, the well was washed with PBS and the cells were fixed with $20 \%$ formalin. Then, the wells were washed with PBS and cells were stained with crystal violet for $30 \mathrm{~min}$. After washing with water, the crystal violet dye was extracted with $30 \%$ acetic acid and the absorbance at $590 \mathrm{~nm}$ was measured.

Invasion assay. Invasion of tumor cells through the reconstituted basement membrane, Matrigel, was assessed in transwell cell culture chambers. ${ }^{16}$ In brief, polyvinylpyrrolidone-free carbonate filters of $8.0 \mu \mathrm{m}$ pore size (Nucleopore, Pleasanton, CA, USA) were mounted in the transwell chambers (Costar 3422, Cambridge, MA, USA). The lower surface of the filters was coated with $20 \mu \mathrm{g}$ of fibronectin and the upper surface was coated with $5 \mu \mathrm{g}$ of Matrigel (Collaborative Research Inc., Bedford, MA, USA). Exponentially growing colon 26-L5 cells were harvested and resuspended in RPMI containing 1\% FCS and various concentrations of brartemicin and its analogs. One hundred microlitres of cell suspension $\left(2 \times 10^{4}\right.$ cells per chamber $)$ was then added to the upper chamber and incubated in a 24 -well culture plate at $37^{\circ} \mathrm{C}$ for $6-8 \mathrm{~h}$. At the end of incubation, the cells on the filters were fixed with methanol and stained with hematoxylin for $3 \mathrm{~min}$ and eosin for $10 \mathrm{~s}$. After gentle rinsing with water, the cells remaining in the Matrigel were removed by wiping the upper chamber with a cotton swab. The filters containing the stained cells that had invaded or migrated through the lower surface were removed from the transwell chambers. The number of the invaded or migrated cells was counted in five different fields of each well under the microscope.

\section{ACKNOWLEDGEMENTS}

This work was supported by the National Natural Science Foundation of China (NSFC, Grant No. 81072517).
1 Steeg, P. S. \& Theodorescu, D. Metastasis: a therapeutic target for cancer. Nat. Clin. Pract. Oncol. 5, 206-219 (2008).

2 Geiger, T. R. \& Peeper, D. S. Metastasis mechanisms. Biochim. Biophys. Acta. 1796, 293-308 2009.

3 Elvin, P. \& Garner, A. P. Tumour invasion and metastasis: challenges facing drug discovery. Curr. Opin. Pharmacol. 5, 374-381 (2005).

4 Hayot, C. et al. Characterization of the activities of actin-affecting drugs on tumor cell migration. Toxicol. Appl. Pharm. 211, 30-40 (2006).

5 Bracke, M. E. et al. Plant polyphenolics as anti-invasive cancer agents. Anticancer Agents Med. Chem. 8, 171-185 (2008).

6 Jiang, Y. -L. \& Liu, Z. -P. Natural products as anti-invasive and anti-metastatic agents. Curr. Med. Chem. 18, 808-829 (2011).

7 Igarashi, Y. et al. Brartemicin, an inhibitor of tumor cell invasion from the actinomycete nonomuraea sp. J. Nat. Prod. 72, 980-982 (2009).

8 Jiang, Y. -L. et al. Synthesis and evaluation of trehalose-based compounds as antiinvasive agents. Bioorg. Med. Chem. Lett. 21, 1089-1091 (2011).

9 Khan, A. A., Stocker, B. L. \& Timmer, M. S. M. Trehalose glycolipids-synthesis and biological activities. Carbohydr. Res. 356, 25-36 (2012).

$10 \mathrm{Khan}, \mathrm{A}$. A. et al. Long-chain lipids are required for the innate immune recognition of trehalose diesters by macrophages. ChemBioChem 12, 2572-2576 (2011).

11 Gilbertson, S. R. \& Chang, C. -W. T. Synthesis of new disugar phosphine ligands and their use in asymmetric hydrogenation. J. Org. Chem. 60, 6226-6228 (1995).

12 Mitsunobu, 0 . The use of diethyl azodicarboxylate and triphenylphosphine in synthesis and transformation of natural products. Synthesis (Mass) 1, 1-28 (1981).

13 Kumara Swamy, K. C., Bhuvan Kumar, N. N., Balaraman, E. \& Pavan Kumar, K. V. P. Mitsunobu and related reactions: advances and applications. Chem. Rev. 109, 2551-2651 (2009).

14 Gensler, W. J. \& Alam, I. Trehalose covalently conjugated to bovine serum albumin. J. Org. Chem. 42, 130-135 (1977).

15 Miyanaga, S. et al. Absolute configuration and antitumor activity of myxochelin A produced by Nonomuraea pusilla TP-A0861. J. Antibiot. 59, 698-703 (2006).

16 Saito, K. -I. et al. A modified and convenient method for assessing tumor cell invasion and migration and its application to screening for inhibitors. Biol. Pharm. Bull. 20, 345-348 (1997). 